\title{
Macrophage Toll-like Receptor 9 Contributes to Chemotherapy-Induced Neuropathic Pain in Male Mice
}

\author{
Xin Luo, ${ }^{1}$ Yul Huh, ${ }^{1,2}$ Sangsu Bang, ${ }^{1}$ Qianru He, ${ }^{1}$ Linlin Zhang, ${ }^{1}$ Megumi Matsuda, ${ }^{1}$ and Ru-Rong Ji1 ${ }^{1,2,3}$ \\ ${ }^{1}$ Center for Translational Pain Medicine, Department of Anesthesiology, ${ }^{2}$ Department of Cell Biology, and ${ }^{3}$ Department of Neurobiology, Duke University \\ Medical Center, North Carolina 27710
}

Chemotherapy-induced peripheral neuropathy (CIPN) remains a pressing clinical problem; however, our understanding of sexual dimorphism in CIPN remains unclear. Emerging studies indicate a sex-dimorphic role of Toll-like receptor 4 (TLR4) in driving neuropathic pain. In this study, we examined the role of TLR9 in CIPN induced by paclitaxel in WT and Tlr9 mutant mice of both sexes. Baseline pain sensitivity was not affected in either Tlr9 mutant male or female mice. Intraplantar and intrathecal injection of the TLR9 agonist ODN 1826 induced mechanical allodynia in both sexes of WT and Tlr4 KO mice but failed to do so in Tlr9 mutant mice. Moreover, Trpv1 KO or C-fiber blockade by resiniferatoxin failed to affect intraplantar ODN 1826-induced mechanical allodynia. Interestingly, the development of paclitaxel-evoked mechanical allodynia was attenuated by TLR9 antagonism or Tlr9 mutation only in male mice. Paclitaxel-induced CIPN caused macrophage infiltration to DRGs in both sexes, and this infiltration was not affected by Tlr 9 mutation. Paclitaxel treatment also upregulated TNF and CXCL1 in macrophage cultures and DRG tissues in both sexes, but these changes were compromised by Tlr 9 mutation in male animals. Intraplantar adoptive transfer of paclitaxel-activated macrophages evoked mechanical allodynia in both sexes, which was compromised by Tlr9 mutation or by treatment with TLR9 inhibitor only in male animals. Finally, TLR9 antagonism reduced paclitaxel-induced mechanical allodynia in female nude mice (T-cell and B-cell deficient). Together, these findings reveal sex-dimorphic macrophage TLR9 signaling in chemotherapy-induced neuropathic pain.

Key words: chemotherapy; DRG; macrophages; neuropathic pain; sex dimorphism; TLR9

\section{Significance Statement}

Chemotherapy-induced peripheral neuropathy (CIPN) is a major side effect in cancer patients undergoing clinical chemotherapy treatment regimens. The role of sex dimorphism with regards to the mechanisms of CIPN and analgesia against CIPN remains unclear. Previous studies have found that the infiltration of immune cells, such as macrophages into DRGs and their subsequent activation promote CIPN. Interestingly, the contribution of microglia to CIPN appears to be limited. Here, we show that macrophage TLR9 signaling promotes CIPN in male mice only. This study suggests that pathways in macrophages may be sex-dimorphic in CIPN. Our findings provide new insights into the role of macrophage signaling mechanisms underlying sex dimorphism in CIPN, which may inspire the development of more precise and effective therapies.

\section{Introduction}

Sex dimorphism in chronic pain is a clinically observed phenomenon, with the majority of patients suffering from pathological chronic pain conditions being women as opposed to men (Bartley and Fillingim, 2013). However, the majority of laboratory pain research has been conducted in male animals, which has led

\footnotetext{
Received Dec. 29, 2018; revised May 31, 2019; accepted June 18, 2019.

Author contributions: X.L., S.B., M.M., and R.-R.J. designed research; X.L., S.B., Q.H., L.Z., and M.M. performed

research; X.L., Y.H., S.B., Q.H., L.Z., M.M., and R.-R.J. analyzed data; R.-R.J., X.L., and Y.H. wrote the paper.

This work was supported by National Institutes of Health R01 Grants NS87988, DE17794, and DE22743.

The authors declare no competing financial interests.

Correspondence should be addressed to Ru-Rong Ji at ru-rong.ji@duke.edu or Xin Luo at xin.luo@duke.edu.

https://doi.org/10.1523/JNEUROSCI.3257-18.2019

Copyright $\odot 2019$ the authors
}

to incomplete translational outcomes from preclinical studies (Mogil, 2012). Currently, spinal neuroimmune interactions are considered to be a major cause of sex differences found in pathological pain. Notably, microglia drive neuropathic pain and inflammatory pain in male animals (Rosen et al., 2017). Several microglial signaling molecules, including Toll-like receptor 4 (TLR4), p38 mitogen-activated protein kinase (MAPK), ATP receptor P2X4, and BDNF, exhibit sexually dimorphic functions in inflammatory and neuropathic pain (Sorge et al., 2011, 2015; Taves et al., 2016; Luo et al., 2018; Mapplebeck et al., 2018; Inyang et al., 2019). Upstream activators of microglia, such as caspase-6, also display male-specific activity in the contexts of inflammatory and neuropathic pain (Berta et al., 2016; Chen et al., 2018). In female animals, $\mathrm{T}$ cells are thought to mediate pathological pain 
(Rosen et al., 2017). For both male and female mice, nerve injury induces the same degree of astrocyte activation, as measured by GFAP expression in the spinal cord, and inhibitors of astroglial signaling have been found to reduce inflammatory and neuropathic pain (Chen et al., 2018). However, a lack of astrocyte activation in female rats after nerve injury has also been reported (Gutierrez et al., 2013). Currently, it is unclear whether other immune cells or glial cells, including macrophages, have sexdimorphic roles in chronic pain.

Chemotherapy-induced peripheral neuropathy (CIPN) is a somatosensory dysfunction caused by chemotherapeutic reagents, such as vincristine (Postma et al., 1993), bortezomib (Cata et al., 2007), cisplatin (Cavaletti et al., 1995), and paclitaxel (PTX) (Forsyth et al., 1997). Clinically, CIPN can cause premature termination or reduced dosage of chemotherapy regimens, leading to poorer survival rates in patients being treated for cancer (Seretny et al., 2014). Recent studies have indicated that multiple types of immune cells, including macrophages, are recruited to the DRGs following chemotherapy (Liu et al., 2014; Zhang et al., 2016). Furthermore, depletion of macrophages alleviated neuropathic pain and downregulated the levels of TNF found in DRGs of chemotherapy-treated animals (Zhang et al., 2016). Additionally, macrophage depletion prevents vincristine-induced CIPN (Old et al., 2014), although it remains unclear whether macrophage activity in CIPN differs between males and females.

The TLR family plays a critical role in innate immune responses by recognizing pathogen-associated molecular patterns and dangerassociated molecular patterns, signaling for the activation of host defense and inflammatory processes against infective pathogens and tissue injuries (Akira et al., 2006). Several TLRs, including TLR2 (Kim et al., 2007), TLR3 (Liu et al., 2012b), TLR4 (Tanga et al., 2005; Sorge et al., 2011; Li et al., 2014, 2015a), TLR5 (Xu et al., 2015; Das et al., 2016), TLR7 (Park et al., 2014), and TLR8 (Zhang et al., 2018), as well as TLR signaling adaptor proteins, such as MyD88 (Stokes et al., 2013; Liu et al., 2014, 2016), have been implicated in pathological pain conditions via immune, glial, and neuronal regulatory mechanisms (for review, see Liu et al., 2012a; Nicotra et al., 2012; Bruno et al., 2018).

Currently, there is a limited understanding of the role TLR9 takes part in pain regulation. TLR9 is localized to endolysosomes and detects endocytosed single-stranded DNA-containing CpG motifs derived from bacterial DNA (Krieg, 2002). Recently, TLR9 was shown to promote transient receptor potential cation channel subfamily member V1 (TRPV1) activation on DRG neurons, with antagonism of TLR9 reducing thermal hyperalgesia induced by cancer (Qi et al., 2011) and spinal cord injury (David et al., 2013). To date, TLR9 signaling in macrophages and sex dimorphism of TLR9 in pathological pain have not been investigated.

In this study, we tested the involvement of TLR9 in PTXinduced neuropathic pain in WT and Tlr9 mutant mice of both sexes. Our results revealed a male-specific contributive role of TLR9 in CIPN via macrophage signaling.

\section{Materials and Methods}

Animals and chemotherapy-induced peripheral neuropathic pain model. Tlr9 mutant mice (C57BL/6J-Tlr $9^{\text {M7Btr }} / \mathrm{Mmjax}$, stock \#34329) and WT control mice (C57BL/6J, stock \#000664) were purchased from The Jackson Laboratory. The Tlr 9 mutant mice used in this study were generated by $\mathrm{N}$-ethyl-N-nitrosourea mutagenesis, a forward genetic approach, by Dr. Bruce Beutler's laboratory. These mice have served as an animal model of Tlr9 deficiency in several recent publications (Brennan et al.,

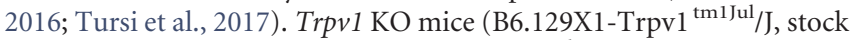
$\# 003770$ ) and nude mice (NOD.CB17-Prkdc scid/J, stock \#001303) were purchased from The Jackson Laboratory. Tlr4 KO mice (homozygous and heterozygous) were gifted by Dr. Cagla Eroglu of Duke University. Adult male and female CD1 and C57BL/6B mice ( 8 weeks old) were purchased from Charles River Laboratories. Animals were randomly assigned to each group. All animals were maintained by the Division of Laboratory Animal Resources at the Duke University Animal Facility. All animal experiments were approved by the Institutional Animal Care and Use Committees of Duke University. CIPN was induced in mice by a single intraperitoneal injection of PTX (Sigma-Aldrich) at a dose of 6 $\mathrm{mg} / \mathrm{kg}$ as previously described (Luo et al., 2018).

Drugs and administration. ODN 1826 and ODN 2088 were purchased from Invivogen. Lipopolysaccharide, resiniferatoxin, and PTX were purchased from Sigma-Aldrich. For intrathecal injections, mice were briefly anesthetized with isoflurane (2\%) and a lumbar puncture was performed between the L5 and L6 spinal levels to deliver drugs $(10 \mu \mathrm{l})$ or cells $(1 \times$ $10^{5}$ in $10 \mu \mathrm{l} \mathrm{PBS}$ ) using a $30 \mathrm{G}$ needle. Intraplantar injections were performed on the plantar surface of a hindpaw ( $10 \mu \mathrm{l})$ using a $30 \mathrm{G}$ needle.

Behavioral analysis. For von Frey testing, animals were habituated in boxes on an elevated metal mesh floor under stable room temperature and humidity at least $2 \mathrm{~d}$ before experiments. Logarithmically graded von Frey fibers (0.02-2.56 g, Stoelting) were applied to the plantar surface of the hindpaw. Paw withdrawal threshold was calculated following the previously reported protocol using the up-down method (Luo et al., 2018). Paw withdrawal frequency was measured by applying a 0.16 or $0.4 \mathrm{~g}$ von Frey filament to the plantar surface of the hindpaw 10 times with the number of paw withdrawals divided by the 10 applications and reported as the withdrawal frequency. Thermal hyperalgesia was measured by Hargreaves test using a Hargreaves radiant heat apparatus (IITC Life Science) with a measurement cutoff of $20 \mathrm{~s}$ to prevent overheatinginduced tissue damage. Hotplate testing was performed to assess heat sensitivity in naive WT and mutant mice with a measurement cutoff of $40 \mathrm{~s}$ (Bioseb) following the protocol as reported previously (Han et al., 2016). Motor function was evaluated by the rotarod test using a rotarod system (IITC Life Science) (Chen et al., 2015). Mice underwent a $2 \mathrm{~d}$ training period ( 2 trials per mouse, $5 \mathrm{rpm}$ rotarod for $10 \mathrm{~min}$ per trial) before the test. During rotarod testing, the speed of rotation was accelerated from 5 to $15 \mathrm{rpm}$ over $60 \mathrm{~s}$ with a testing period cutoff of $300 \mathrm{~s}$ for each trial and 2 total trials performed. The fall latency of each mouse was recorded and averaged. The experimenter was blinded to the treatments given to each mouse.

Peritoneal macrophage culture. Peritoneal macrophages were collected from animals by peritoneal lavage with $10 \mathrm{ml}$ of warm PBS containing 1 mM of EDTA as previously reported (Bang et al., 2018). Cells were incubated in DMEM supplemented with $10 \%$ FBS at $37^{\circ} \mathrm{C}$ for $2 \mathrm{~h}$ in a Petri dish and washed with PBS to eliminate nonadherent cells. Adherent cells were used in subsequent experiments as peritoneal macrophages following $3 \mathrm{~d}$ of culture.

ELISA. Mouse ELISA kits for TNF and CXCL-1 were purchased from R\&D Systems. ELISA tests were performed using DRG tissue lysates, serum samples, and cell media. DRG tissues were homogenized in a lysis buffer containing protease and phosphatase inhibitors. Serum was obtained from facial vein whole blood and allowed to clot for $30 \mathrm{~min}$ at room temperature. The clot was then removed by refrigerated centrifuge at $2000 \times g$ for $10 \mathrm{~min}$ to collect the supernatant (serum). The cell culture medium was collected at a volume of $200 \mu \mathrm{l}$ per sample after application of $1 \mu \mathrm{g} / \mathrm{ml}$ lipopolysaccharide and $100 \mathrm{nM}$ PTX in $1 \times 10^{5}$ seeding cells. For each ELISA assay, $50 \mu \mathrm{g}$ of protein, $50 \mu \mathrm{l}$ of culture medium, or $5 \mu \mathrm{l}$ of serum was used. ELISA tests were conducted according to the manufacturer's instructions. The standard curve was included in each experiment.

Flow cytometry. DRG tissues were obtained from adult Tlr9 mutant and WT mice and placed in $1 \mathrm{mg} / \mathrm{ml}$ collagenase A and $2.4 \mathrm{U} / \mathrm{ml}$ Dispase II (Roche Diagnostics) in HBSS. Tissues were incubated at $37^{\circ} \mathrm{C}$ with continuous shaking at $100 \mathrm{rpm}$ for $60 \mathrm{~min}$. The cells were dissociated by pipette, washed with HBSS and 0.5\% BSA, filtered through a $70 \mu \mathrm{m}$ mesh cell strainer, and treated with $1 \times$ RBC lysis buffer (BioLegend) to reduce $\mathrm{RBC}$ contamination. Surface expression of F4/80 and CD11b was analyzed by flow cytometry. Dissociated DRGs and peritoneal cells were counted with $2 \times 10^{6}$ cells per sample blocked by Fc receptor staining buffer (1\% anti-mouse CD16/CD32, 2.4 G2, 2\% FBS, 5\% NRS, and 2\% 
Table 1. Antibodies for flow cytometry

\begin{tabular}{llll}
\hline & & Laser $488 \mathrm{~nm}$ & Laser $633 \mathrm{~nm}$ \\
\hline Experiment & Filter & $530 / 30 \mathrm{~nm}$ & $660 / 20 \mathrm{~nm}$ \\
DRG, MØ & Primary antibody & F4/80-FITC & CD11b-APC \\
\hline
\end{tabular}

Table 2. Antibodies for FACS

\begin{tabular}{llll}
\hline & Company & Catalog no. & Dilution \\
\hline $\begin{array}{llll}\text { FACS primary antibody } \\
\text { Rat anti-CD11b-APC }\end{array}$ & BioLegend & 101211 & $1: 200$ \\
$\begin{array}{l}\text { Rat anti-mouse-F4/80-FITC } \\
\text { FACS control antibody }\end{array}$ & BioLegend & 123107 & $1: 200$ \\
$\quad$ Rat anti-mouse lgG-FITC & BD Biosciences & $51-20415 z$ & $1: 200$ \\
Donkey anti-mouse IgG-Cy5 & Jackson ImmunoResearch & $715-175-151$ & $1: 200$ \\
& Laboratories & & \\
\hline
\end{tabular}

NMS in HBSS; BD Biosciences) and then stained with a corresponding standard panel of antibodies (Tables 1,2 ) for $30 \mathrm{~min}$ at $4^{\circ} \mathrm{C}$. After staining, cells were washed in PBS with EDTA. Flow cytometry events were acquired in a BD FACS Canto II flow cytometer using BD FACS Diva 8 software (BD Biosciences). Data were analyzed by Cytobank Software (https://www.cytobank.org/cytobank).

Immunohistochemistry. Mice were anesthetized with isoflurane and perfused through the ascending aorta with PBS followed by $4 \%$ PFA. After perfusion, DRG tissues were postfixed, dehydrated with $30 \%$ sucrose solution, embedded, and sliced into $14 \mu \mathrm{m}$ tissue sections with a cryostat. The sections were blocked with $5 \%$ goat serum for $1 \mathrm{~h}$ at room temperature and incubated overnight at $4^{\circ} \mathrm{C}$ with primary $\mathrm{F} 4 / 80$ monoclonal antibody (rat, 1:100, Invitrogen). After washing, the sections were incubated with secondary goat anti-rat IgG antibody (1:500, Invitrogen) for $2 \mathrm{~h}$ at room temperature. DAPI (1:1000, Vector Laboratories) was used to stain cell nuclei. Stained tissue sections were examined using a Nikon fluorescence microscope. To quantify macrophage infiltration in DRGs, F4/80-labeled cells were counted within an area of $180 \mu \mathrm{m} \times 180$ $\mu \mathrm{m}$ in each optic field and calculated as the number of macrophages per $\mathrm{mm}^{2}$ of tissue. Three or four DRG sections were counted per mouse, and 3 mice were included per group.

Statistics. All data are expressed as the mean \pm SEM. The sample size for each experiment is indicated in the figure legends. Behavioral test data were analyzed by one-way or two-way ANOVA, followed by Bonferroni's post hoc test. FACS and ELISA data were analyzed by two-way ANOVA, followed by Bonferroni's post hoc test. A $p$ value of $<0.05$ was considered statistically significant.

\section{Results}

\section{Tlr9 mutation does not affect the baseline pain threshold of} male or female mice

We tested the baseline thermal pain sensitivity of Tlr9 mutant mice for both sexes. The hotplate test $\left(53^{\circ} \mathrm{C}\right)$ showed that the withdrawal latency was not affected in both male and female Tlr 9 mutant mice compared with WT mice (Fig. $1 A ; F_{(3,22)}=2.580$, $p>0.05$, one-way ANOVA). The acetone test showed that Tlr 9 mutant mice exhibited normal response to cold stimulus (Fig. 1B; $F_{(3,16)}=0.2222, p>0.05$, one-way ANOVA). Furthermore, $\operatorname{Tl} r 9$ mutant mice exhibited normal motor function compared with WT mice in the rotarod test (Fig. $1 C ; F_{(3,18)}=0.9580, p>0.05$, one-way ANOVA). von Frey testing for mechanical pain sensitivity also showed no differences in baseline paw withdrawal thresholds between WT and mutant mice of both sexes (Fig. 2A-D). Together, these data suggest that $T l r 9$ mutation does not affect nociceptive threshold under physiological conditions for both male and female mice.

\section{Intraplantar or intrathecal injection of TLR9 agonist ODN 1826 induces mechanical allodynia in WT mice but not in Tlr9 mutant mice of both sexes}

As a component of the innate immune system, TLR9 detects unmethylated CpG motifs present on bacterial DNA. Synthetic oligodeoxynucleotides with CpG motifs (CpG ODNs) have been developed as TLR9 agonists, including Class A (e.g., ODN 2216), Class B (e.g., ODN 1826), and Class C (e.g., ODN 2395) (Krieg, 2006). In particular, intrathecal administration of ODN 1826 evokes potent inflammatory responses in the spinal cord (David et al., 2013). We investigated the effects of ODN 1826 on nociceptive threshold as measured by von Frey testing. Intraplantar injection of $5 \mu \mathrm{g}$ of ODN 1826 induced mechanical allodynia when measured at $5 \mathrm{~h}$ after injection in WT mice of both sexes, but not in Tlr9 mutant mice of either sex (Fig. $2 A, B ; F_{(4,40)}=$ 16.59 in Fig. $2 A$ and $F_{(4,40)}=12.05$ in Fig. $2 B ; p<0.001$, two-way ANOVA). Notably, ODN 1826 failed to evoke mechanical allodynia at earlier testing time points ( 1 and 3 h; Fig. $2 A, B$ ). This delayed response may suggest a mechanism of indirect activation of sensory neurons by this TLR9 ligand.

Intrathecal injection of ODN $1826(5 \mu \mathrm{g})$ also induced mechanical allodynia in WT mice of both sexes but failed to induce mechanical allodynia in Tlr9 mutant mice of either sex (Fig. $2 C, D ; F_{(4,40)}=10.17$ in Fig. $2 C$ and $F_{(5,46)}=10.22$ in Fig. $2 D ; p<$ 0.001 , two-way ANOVA). While mechanical allodynia resolved within $5 \mathrm{~h}$ in male mice after intrathecal administration of ODN 1826, it did not resolve until $48 \mathrm{~h}$ after injection in female mice (Fig. 2C,D). Collectively, these data suggest that ODN 1826 is a selective agonist of TLR9 and is sufficient to evoke mechanical allodynia in both sexes via both peripheral and central mechanisms.

\section{TLR9 agonist ODN 1826 induces mechanical allodynia in Tlr4} mutant mice of both sexes

TLR4 is one of the best characterized members of the TLR family and has been strongly implicated in the pathogenesis of pain in different animal models (Tanga et al., 2005; Christianson et al., 2011; Stokes et al., 2013; Bruno et al., 2018). To further explore whether TLR9 signaling is dependent on TLR4, we assessed the behavioral effects of ODN 1826 treatment in Tlr4 KO mice. Intrathecal or intraplantar injection of $10 \mu \mathrm{g}$ of ODN 1826 induced mechanical allodynia in both male and female Tlr4 KO heterozygous and homozygous mice. Interestingly, we found that Tlr $4 \mathrm{KO}$ potentiated mechanical allodynia caused by ODN 1826 compared with control (heterozygous) counterparts (Fig. 3A-D; Fig. $3 A: F_{(5,42)}=32.13$; Fig. $3 B: F_{(5,42)}=34.64$; Fig. $3 C: F_{(5,42)}=16.68$; Fig. $3 D: F_{(5,42)}=24.38 ; p<0.05$, two-way ANOVA). Thus, TLR9-mediated pain signaling may be potentiated as a compensatory mechanism for the loss of TLR4 function in Tlr4 KO homozygous mice.

\section{TRPV1 expression and C-fiber signaling are not required for} TLR9 agonist ODN 1826 to induce mechanical allodynia

Recent studies indicate that TLR9 regulates thermal nociception by modulating TRPV1 expression and activities in DRG (Qi et al., 2011). TLR9 may cause mechanical allodynia via TRPV1 in the peripheral nervous system. To verify this hypothesis, we tested the effects of ODN 1826 in Trpv1 KO mice following intraplantar injection. We found that KO of Trpv1 had no effect on mechanical allodynia caused by intraplantar ODN $1826(10 \mu \mathrm{g})$ in mice of both sexes (Fig. $4 A, B ; F_{(4,40)}=8.728$ in Fig. $4 A$ and $F_{(4,40)}=$ 10.64 in Fig. $4 B ; p<0.05$, two-way ANOVA). Next, to define the 
A

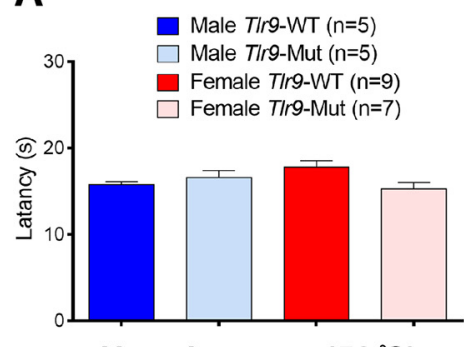

Hot plate test $\left(53^{\circ} \mathrm{C}\right)$
B

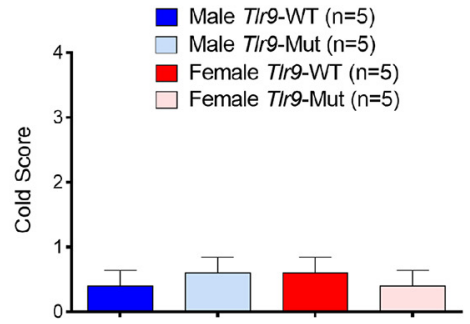

Acetone test

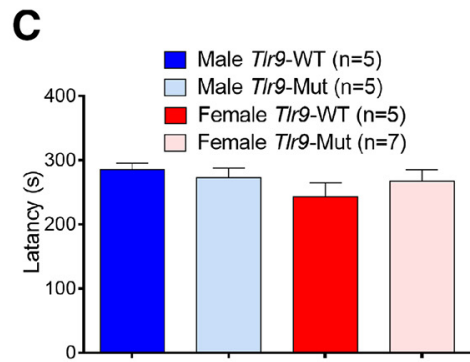

Rotarod test

Figure 1. T/r9 mutation does not affect basal thermal sensitivity and motor function in male and female mice. $\boldsymbol{A}-\boldsymbol{C}, \operatorname{Tr} 9$ mutation did not affect baseline heat sensitivity in hotplate testing $(\boldsymbol{A})$ and cold sensitivity in acetone testing $(\boldsymbol{B})$ in both sexes. $\boldsymbol{C}$, Rotarod testing showed no motor impairment in $7 / r 9$ mutant mice of both sexes. One-way ANOVA with Bonferroni's post hoc test; $n=5-7$ mice per group. Data are mean \pm SEM.
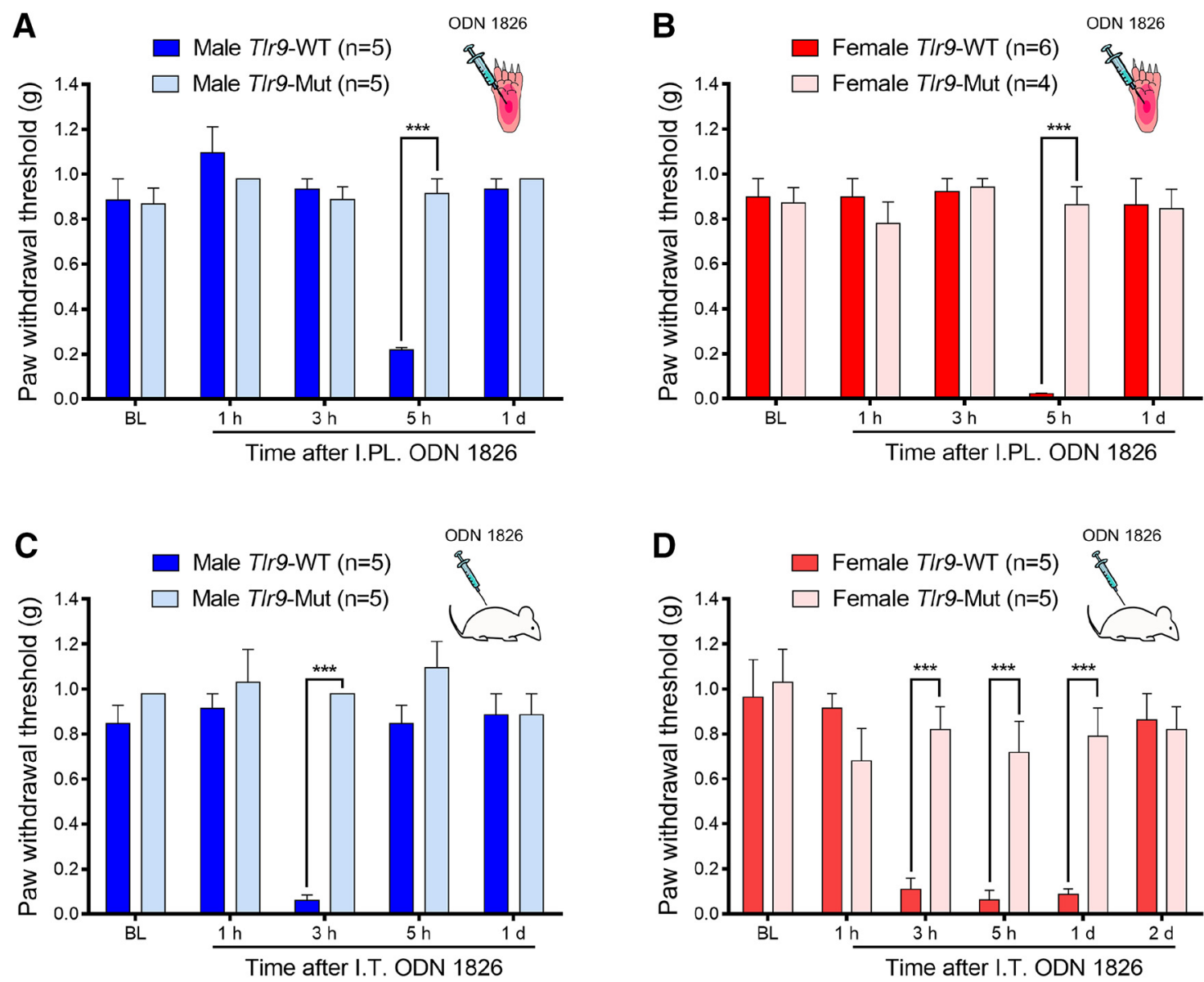

Figure 2. Intraplantar or intrathecal injection of TLR9 agonist ODN 1826 induces mechanical allodynia in WT but not T/r9 mutant mice. $\boldsymbol{A}-\boldsymbol{D}$, Intraplantar (I.PL., $\boldsymbol{A}, \boldsymbol{B})$ and intrathecal (I.T., C, D) injections of $5 \mu \mathrm{g}$ of ODN 1826 decreased the paw withdrawal threshold in both male and female mice, and this effect was inhibited by T/r 9 mutation in male and female mice. ${ }^{* * *} p<0.001$ compared with WT group (two-way ANOVA with Bonferroni's post hoc test). $n=4-6$ mice per group. There are no significant differences in baseline (BL) paw withdrawal thresholds between WT and mutant mice in both sexes. Data are mean \pm SEM.

role of C-fibers in TLR9 agonist-induced pain, we treated mice with resiniferatoxin to block the function of TRPV1-positive C-fibers (Suter et al., 2009). Intraplantar injection of ODN 1826 $(10 \mu \mathrm{g})$ was fully capable of inducing mechanical allodynia in resiniferatoxin-treated mice of both sexes (Fig. $4 C, D ; F_{(5,48)}=$ 14.44 in Fig. $4 C$ and $F_{(5,48)}=7.080$ in Fig. $4 D ; p<0.05$, two-way ANOVA). These findings suggested that TLR9-induced mechanical allodynia does not require TRPV1 expression or signaling of C-fibers.
TLR9 contributes to the development of CIPN in male mice To determine whether TLR9 signaling contributes to CIPN, we administered a single high-dose $(6 \mathrm{mg} / \mathrm{kg})$ intraperitoneal injection of the chemotherapy drug PTX into Tlr9 mutant and WT mice of both sexes. This PTX treatment induced immediate (within $3 \mathrm{~d}$ ) and persistent mechanical allodynia in WT mice of both sexes. Intriguingly, mechanical allodynia fully resolved within 4 weeks in WT male mice treated with PTX, but mechanical allodynia failed to resolve within the same amount of time in 
A

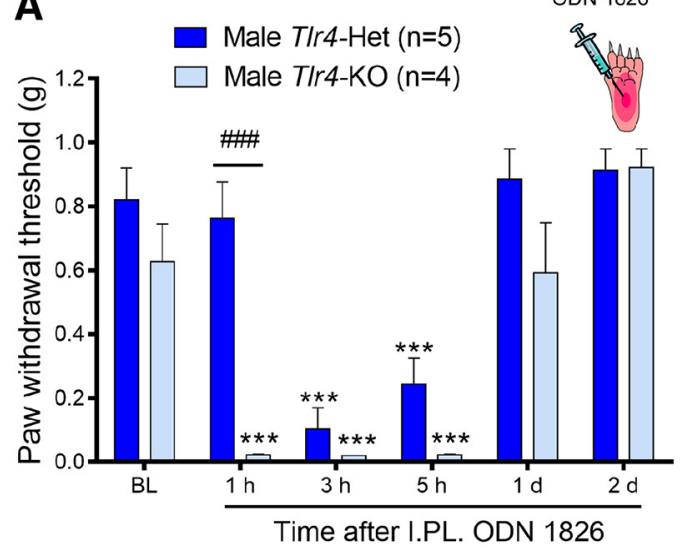

C

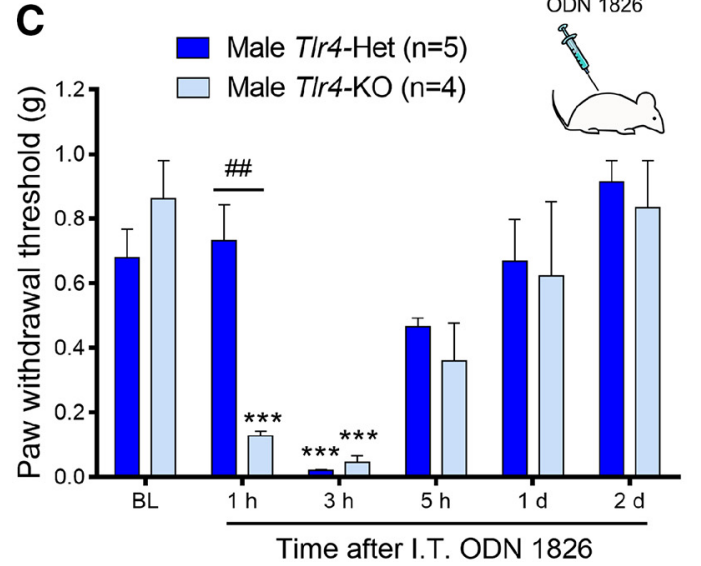

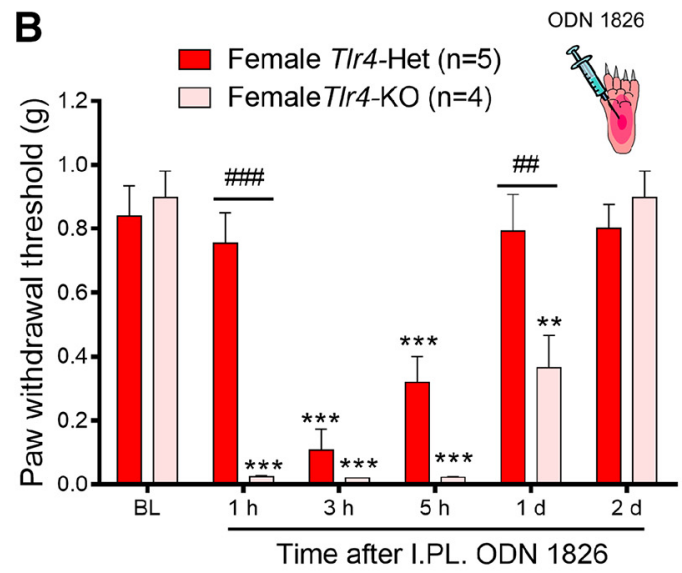

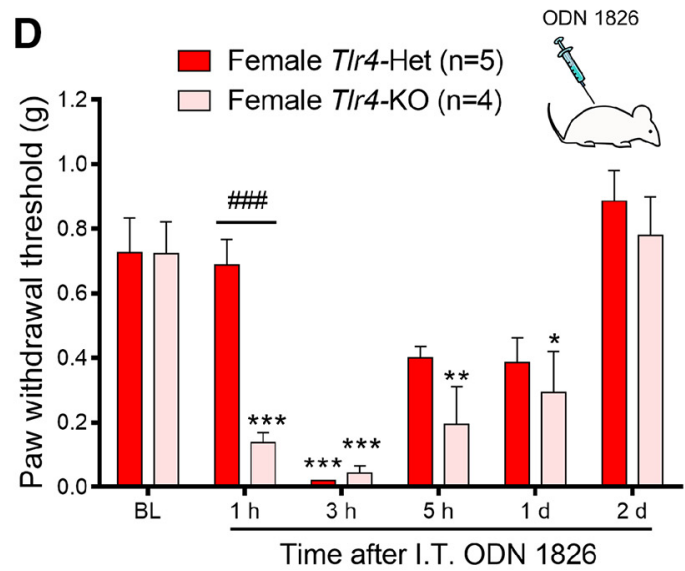

Figure 3. Intraplantar (I.PL.) or intrathecal (I.T.) injection of TLR9 agonist ODN 1826 induces mechanical allodynia in WT and $T / r 4 \mathrm{KO}$ mice. $\boldsymbol{A}-\boldsymbol{D}$, Intraplantar $(\boldsymbol{A}, \boldsymbol{B})$ or intrathecal (C, $\boldsymbol{D})$ injection of $10 \mu \mathrm{g}$ of ODN 1826 reduced the paw withdrawal threshold in both male and female T/r4 heterozygous (control) and homozygous K0 mice. Compared with baseline: ${ }^{* * *} p<0.001 ;{ }^{* *} p<0.01$; ${ }^{*} p<0.05$. Compared with the TIr4 heterozygous group (two-way ANOVA with Bonferroni's post hoc test): ${ }^{\# \# ~} p<0.001$; ${ }^{\# \#} p<0.01 . n=4$ or 5 mice per group. Data are mean \pm SEM.

WT females treated with PTX (Fig. 5A,B). Interestingly, male Tlr9 mutant mice demonstrated delayed onset of mechanical allodynia until day 14 after PTX treatment, whereas female Tlr9 mutant mice did not demonstrate this effect and instead exhibited mechanical allodynia from day 3 after PTX treatment like WT mice (Fig. $5 A, B$; Fig. $5 A: F_{(7,144)}=24.88$; Fig. $5 B: F_{(7,144)}=$ $73.81 ; p<0.01$, two-way ANOVA). Acetone testing showed that PTX treatment also induced sustained cold allodynia in WT mice of both sexes for $>4$ weeks (Fig. $5 C, D$ ). Of note, neither male nor female Tlr9 mutant mice demonstrated changes in PTX-induced cold allodynia compared with WT control mice (Fig. $5 C, D ; F_{(7,64)}$ $=11.20$ in Fig. $5 C$ and $F_{(7,64)}=12.30$ in Fig. $5 D ; p>0.05$, two-way ANOVA).

We next treated mice with the TLR9 antagonist ODN 2088 (Qi et al., 2011; David et al., 2013) via intraplantar or intrathecal injection at a dose of $10 \mu \mathrm{g}$ on day 10 after PTX injection in WT mice of both sexes and evaluated the effects on mechanical sensitivity (Fig. 6A-H). Mechanical allodynia testing by von Frey filaments showed increased paw withdrawal threshold in male PTX-treated mice, which received ODN 2088 compared with vehicle control (Fig. $6 A, C ; F_{(5,60)}=96.29$ in Fig. $6 A$ and $F_{(5,60)}=$ 66.03 in Fig. 6C; $p<0.05$, two-way ANOVA). To further assess the effects of ODN 2088 treatment on mechanical allodynia, we also tested paw withdrawal frequency using a $0.4 \mathrm{~g}$ filament (Fig. $6 E-H)$. The result showed that PTX increased paw withdrawal frequency, which was suppressed by ODN 2088 in male mice compared with vehicle control (Fig. $6 E, G: F_{(5,48)}=46.56$ in Fig. $6 E$ and $F_{(5,60)}=48.48$ in Fig. $\left.6 G\right)$.

However, ODN 2088 injections failed to exhibit any antiallodynic effect in PTX-treated female mice as measured by von Frey testing for paw withdrawal threshold (Fig. $6 B, D ; F_{(5,48)}=110.4$ in Fig. $6 B$ and $F_{(5,60)}=98.41$ in Fig. $6 D ; p>0.05$, two-way ANOVA) and paw withdrawal frequency (Fig. $6 F, H: F_{(5,48)}=$ 67.62 in Fig. $6 F$ and $F_{(5,60)}=138.2$ in Fig. $6 H ; p>0.05$, two-way ANOVA). Therefore, the antiallodynic effects from intraplantar and intrathecal ODN 2088 treatment in PTX-treated mice were observed in male mice but not in female mice.

\section{PTX treatment causes macrophage infiltration into DRGs in WT and Tlr9 mutant mice of both sexes}

The infiltration of macrophages into DRGs contributes to the development of CIPN (Peters et al., 2007; Liu et al., 2010), although whether this is a sex-specific process is unclear. On day 7 after PTX injection, FACS analysis revealed increased counts of cells positive for macrophage markers F4/80 and CD11b in DRGs taken from PTX-treated WT male and female mice, and Tlr9 mutant mice of both sexes showed a similar increase in macrophage DRG infiltration following PTX treatment (Fig. 7A, B; $F_{(1,35)}=49.54 ; p<0.01$, two-way ANOVA). These findings were further confirmed by immunohistochemistry data, which showed that PTX treatment led to an increase of F4/80-postive cells in DRG tissue from WT mice of both sexes as well as Tlr9 

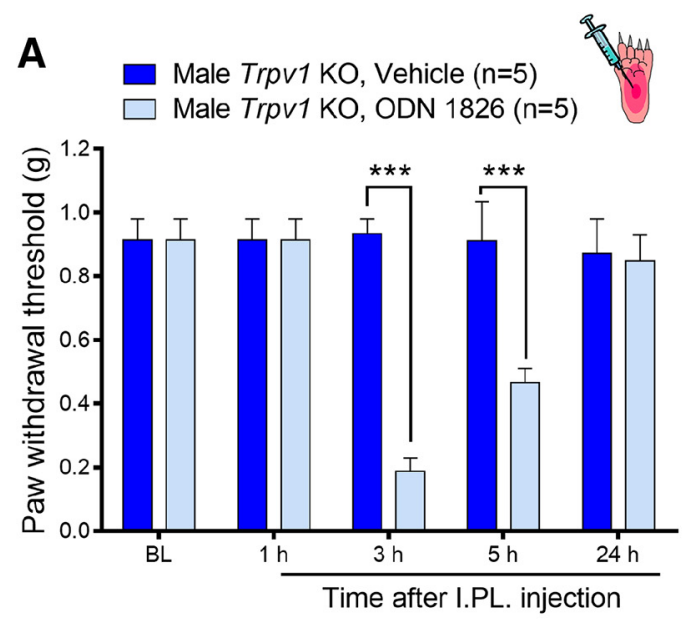

C
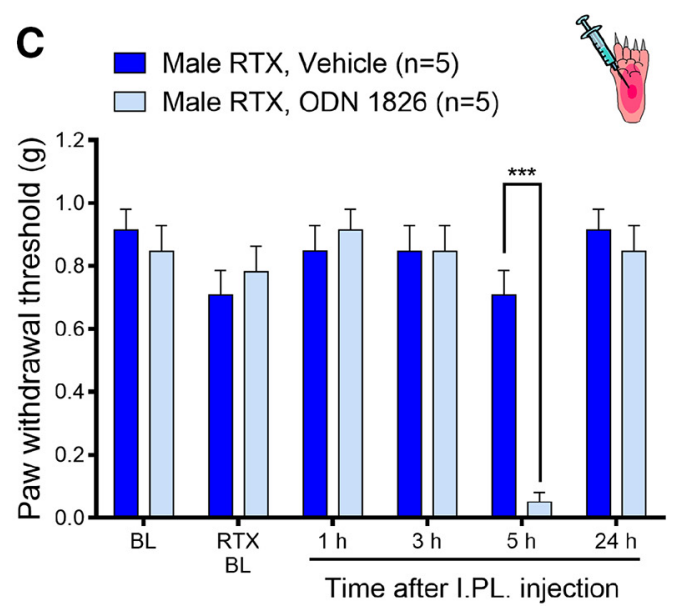
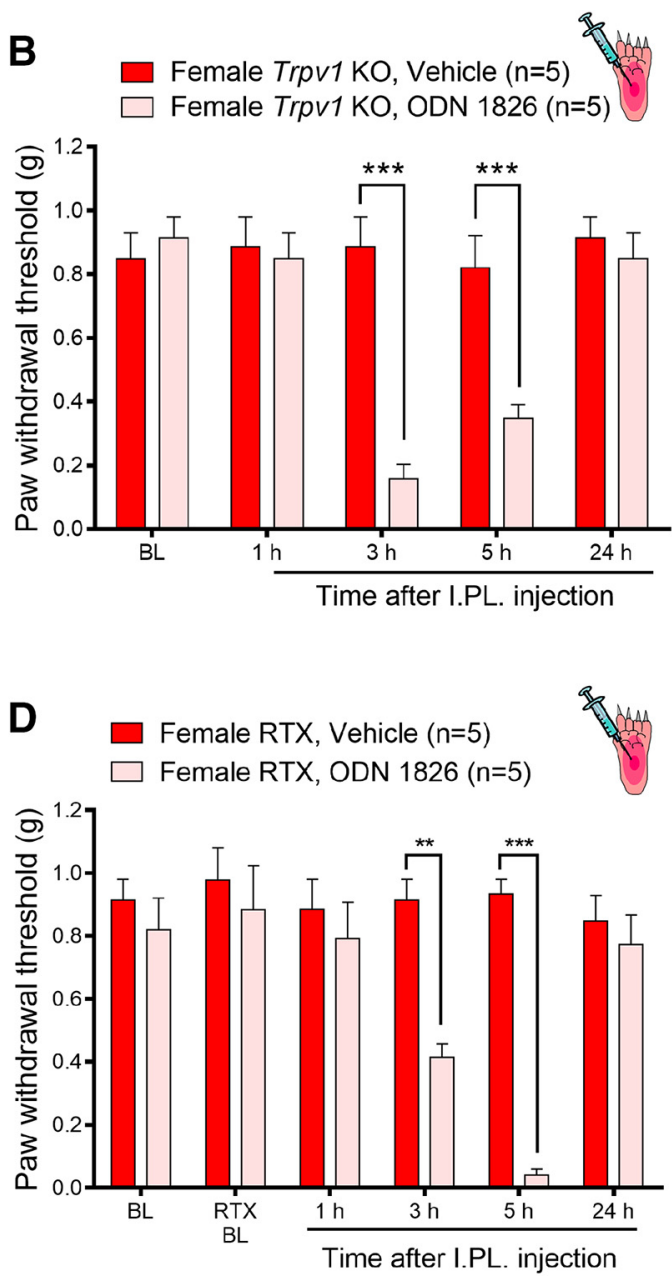

Figure 4. Intraplantar (I.PL.) injection of TLR9 agonist ODN 1826 induces mechanical allodynia in Trpv1 K0 mice and resiniferatoxin-treated mice. $A-D$, Intraplantar injection of $10 \mu$ g of $0 D N$ 1826 reduced the paw withdrawal threshold in Trpv1 K0 mice ( $\boldsymbol{A}$, males; $\boldsymbol{B}$, females) and in mice treated with resiniferatoxin (RTX; $\boldsymbol{C}$, males; $\boldsymbol{D}$, females). Compared with vehicle group (two-way ANOVA with Bonferroni's post hoc test): ${ }^{* * *} p<0.001 ;{ }^{* *} p<0.01 . n=5$ mice per group. Data are mean \pm SEM.

mutant mice of both sexes ( Fig. $7 C, D ; F_{(1,16)}=81.38, p<0.001$, two-way ANOVA). These findings suggest that macrophage infiltration to the DRG following PTX treatment occurs in male and female mice and does not require TLR9.

\section{Adoptive transfer of PTX-primed macrophages induces mechanical allodynia in male, but not female, mice via TLR9} Next, we investigated whether adoptive transfer of PTX-treated macrophages could induce mechanical allodynia and whether this effect is sex-dependent or TLR9-dependent. To define a direct action of PTX on macrophages, peritoneal macrophages were collected from naive C57BL/6B mice of both sexes (donor), cultured, and treated with or without PTX $(2 \mathrm{mg} / \mathrm{ml}, 16 \mathrm{~h})$ in vitro. Then, the naive macrophages and PTX-treated (primed) macrophages were harvested from culture for intraplantar injections at a dose of $5 \times 10^{4}$ cells per injection into naive $\mathrm{C} 57 \mathrm{BL} / 6 \mathrm{~B}$ mice (receiver). Macrophages from male donor animals were injected into male receiver mice, and macrophages from female donor animals were injected into female receiver mice (Fig. 8A). Intraplantar injection of WT macrophages caused a mild and transient decrease in paw withdrawal threshold for several hours in both sexes. By contrast, intraplantar injection of PTX-primed macrophages caused a substantial and persistent reduction of withdrawal threshold (mechanical allodynia) in both male and female receiver mice for $>24 \mathrm{~h}$ (Fig. $8 \mathrm{~B}, \mathrm{C}$ : $F_{(3,32)}=17.91$ in Fig. $8 B$ and $F_{(3,32)}=19.90$ in Fig. $8 C ; p<$ 0.05, two-way ANOVA).

Next, we tested whether mechanical allodynia induced by the PTX-primed macrophages is mediated by TLR9. On day 2 after adoptive transfer of primed macrophages, intraplantar injections of ODN $2088(10 \mu \mathrm{g})$ transiently reversed mechanical allodynia in male mice but failed to reverse mechanical allodynia in female mice (Fig. $8 D, E ; F_{(3,32)}=5.530$ in Fig. $8 D$ and $F_{(3,32)}=0.3472$ in Fig. $8 E ; p<0.001$, two-way ANOVA). To further investigate the role of TLR9 in this phenomenon, peritoneal macrophages were collected from naive WT and Tlr9 mutant mice of both sexes (donor), cultured in vitro, and treated with PTX $(2 \mathrm{mg} / \mathrm{ml}, 16 \mathrm{~h})$. Then, the PTX-treated (primed) WT and Tlr9 mutant macrophages were harvested for intraplantar or intrathecal injections at a dose of $5 \times 10^{4}$ cells per injection into naive C57BL/6B mice (receiver). Macrophages from male donor animals were injected into male receiver mice, and macrophages from female donor animals were injected into female receiver mice (Fig. 9A).

While intraplantar injection of PTX-primed WT macrophages caused robust mechanical allodynia in male receiver mice, 

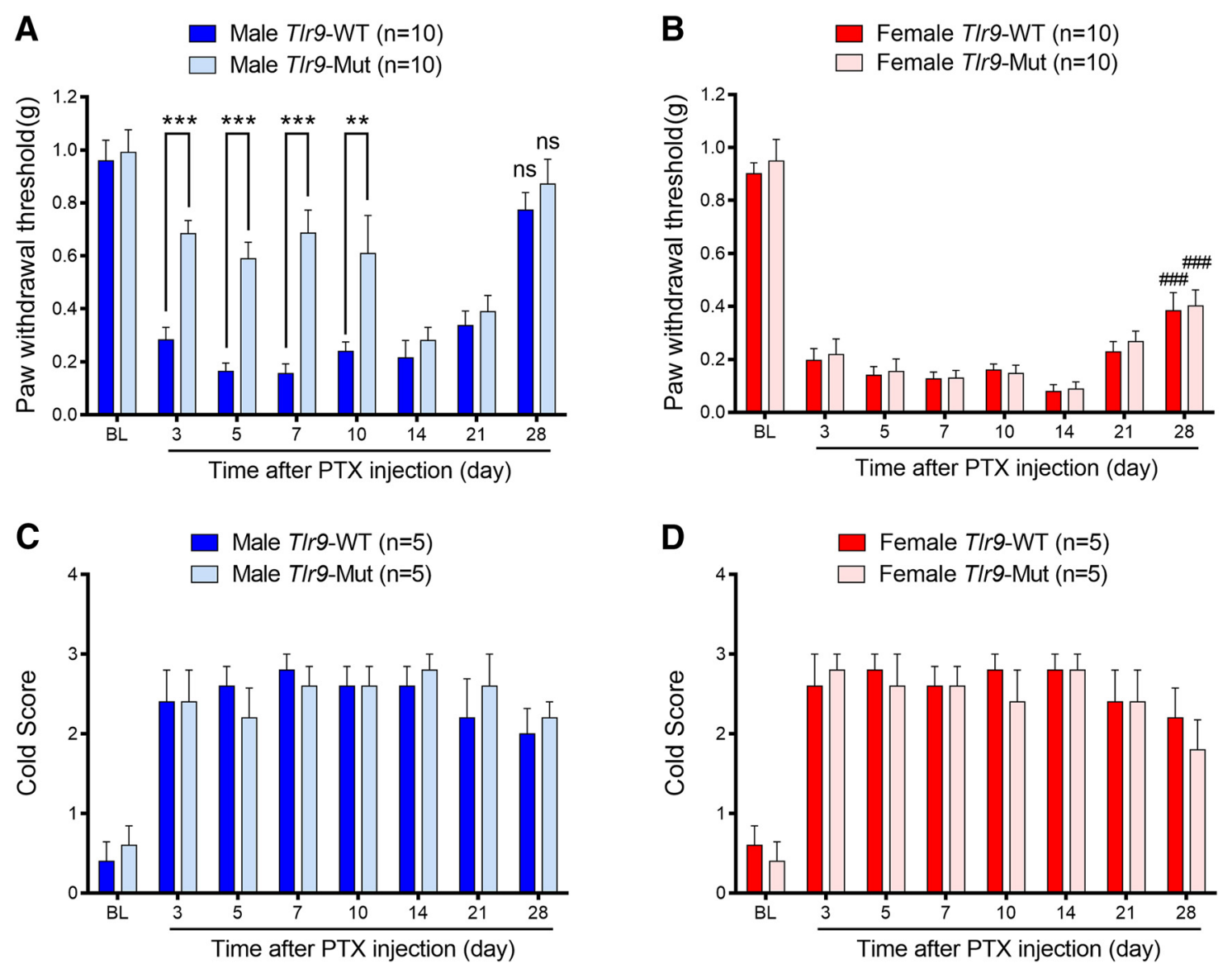

Figure 5. T/r9 mutation delays the onset of paclitaxel (PTX)-induced mechanical allodynia in male mice without affecting cold allodynia. $A, B, T / r 9$ mutation increased paw withdrawal threshold in male mice $(\boldsymbol{A})$ but not in female mice $(\boldsymbol{B})$ within $3 \mathrm{~d}$ following PTX treatment. Mechanical allodynia fully resolved at the 28 days in WT male mice but failed to resolve at this time point in WT female mice $(\boldsymbol{A}, \boldsymbol{B})$. Compared with the vehicle group (two-way ANOVA with Bonferroni's post hoc test): ${ }^{* * *} p<0.001 ;{ }^{* *} p<0.01$. Compared with BL (two-way ANOVA with Bonferroni's post hoc test): $\# \#<0.001 . n=10$ mice per group. $\boldsymbol{C}, \boldsymbol{D}$, TIr9 mutation had no effect on PTX-induced cold allodynia in male mice $(\boldsymbol{C})$ and female mice $(\boldsymbol{D})$. $p>0.05$ (two-way ANOVA with Bonferroni's post hoc test). $n=5$ mice per group. Data are mean \pm SEM. ns, not significant.

in comparison, Tlr9 mutant macrophages were inhibited from inducing mechanical allodynia in male receiver mice (Fig. 9B: $F_{(3,32)}=39.44$; Fig. 9F: $F_{(3,32)}=55.30, p<0.05$, two-way ANOVA). In female receiver mice, intraplantar injection of PTXprimed macrophages also caused mechanical allodynia; and unlike with male Tlr9 mutant macrophages, PTX-primed macrophages from $\operatorname{Tl} 9$ mutant female donor mice were able to induce mechanical allodynia when injected intraplantarly into female receiver mice as measured by the von Frey threshold test (Fig. $9 C ; F_{(3,32)}=138.8, p>0.05$, two-way ANOVA) and von Frey frequency test (Fig. $9 G ; F_{(3,32)}=14.13, p>0.05$, two-way ANOVA).

Furthermore, intrathecal injection of PTX-primed macrophages induced decreased paw withdrawal thresholds in both male and female receiver mice. However, Tlr9 mutant macrophages injected intrathecally were not inhibited from inducing mechanical allodynia in either male or female WT mice (Fig. $9 D, E ; F_{(3,32)}=31.58$ in Fig. $9 D$ and $F_{(3,28)}=47.94$ in Fig. $9 E ; p>$ 0.05 , two-way ANOVA), suggesting that macrophage TLR9 signaling does not exhibit sex dimorphism in the CNS. Together, these results indicated that PTX-primed macrophages evoked pain hypersensitivity for both male and female receiver mice and that macrophage TLR9 signaling may drive CIPN only in male mice via peripheral mechanisms.
Mutation of Tlr9 inhibits PTX-induced increase of TNF and CXCL1 expression in macrophages and DRGs in male mice but not in female mice

Chemotherapeutic reagents have been shown to upregulate cytokine and chemokine release in animals (Makker et al., 2017) and humans (Pusztai et al., 2004). Following chemotherapy, macrophages secrete cytokines and chemokines that drive CIPN (Montague and Malcangio, 2017). TLR9 has been shown to upregulate the expression of TNF and CXCL1 (David et al., 2013), which are two important pronociceptive inflammatory mediators (Huh et al., 2017). We investigated the role of TLR9 in the release of TNF and CXCL1 by analyzing peritoneal macrophage culture medium (in vitro), as well as serum, peritoneal fluid, and DRG tissue (in vivo) from male and female mice following PTX treatment. ELISA quantification showed that treatment of macrophage cultures with PTX $(2 \mathrm{mg} / \mathrm{ml}, 16 \mathrm{~h})$ or lipopolysaccharide $(1 \mu \mathrm{g} / \mathrm{ml}$, $24 \mathrm{~h}$ ) significantly increased the release of TNF and CXCL1 into macrophage culture medium for both sexes. Intriguingly, Tlr9 mutation inhibited the increased release of TNF and CXCL1 in PTX-treated male macrophage cultures (Fig. $10 A, B ; F_{(2,24)}=$ 66.12 in Fig. $10 A$ and $F_{(2,24)}=91.07$ in Fig. $10 B ; p<0.01$, twoway ANOVA). Of note, on day 7 after PTX injection, TNF levels in serum were the same as baseline pre-PTX levels (Fig. 10C; $F_{(1,32)}=0.7667, p>0.05$, two-way ANOVA). 

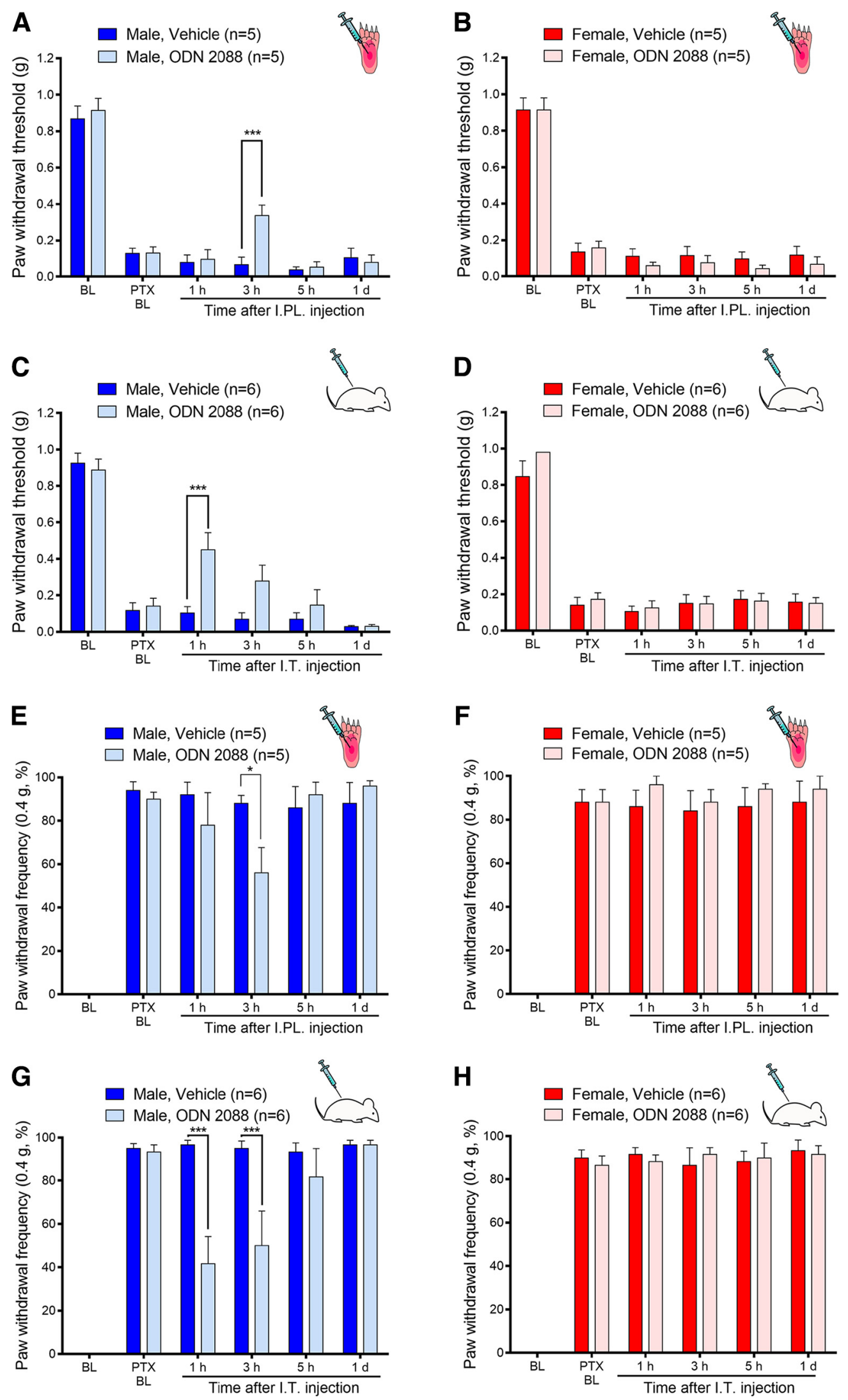

Figure 6. Intraplantar (I.PL.) or intrathecal (I.T.) injection of TLR9 antagonist ODN 2088 reduces PTX-induced mechanical allodynia in male mice but not in female mice. $\boldsymbol{A}-\boldsymbol{D}$, Paw withdrawal threshold. Intraplantar or intrathecal injection of $10 \mu \mathrm{g}$ of ODN 2088 increased the threshold in male mice $(\boldsymbol{A}, \boldsymbol{C})$, but not in female mice $(\boldsymbol{B}, \boldsymbol{D})$, following PTX treatment (after PTX day 10$)$. ${ }^{* * *} p<$ 0.001 compared with vehicle group (two-way ANOVA with Bonferroni's post hoc test). $n=5$ or 6 mice per group. $\boldsymbol{E}-\boldsymbol{H}$, Paw withdrawal frequency. Intraplantar or intrathecal injection of $10 \mu \mathrm{g}$ of ODN 2088 decreased paw withdrawal frequency in male mice $(\boldsymbol{E}, \boldsymbol{G})$, but not in female mice $(\boldsymbol{F}, \boldsymbol{H})$, following PTX treatment (after PTX day 10$)$. Compared with vehicle group (two-way ANOVA with Bonferroni's post hoc test): ${ }^{*} p<0.05 ;{ }^{* * *} p<0.001 . n=5$ or 6 mice per group. Data are mean \pm SEM. 
A

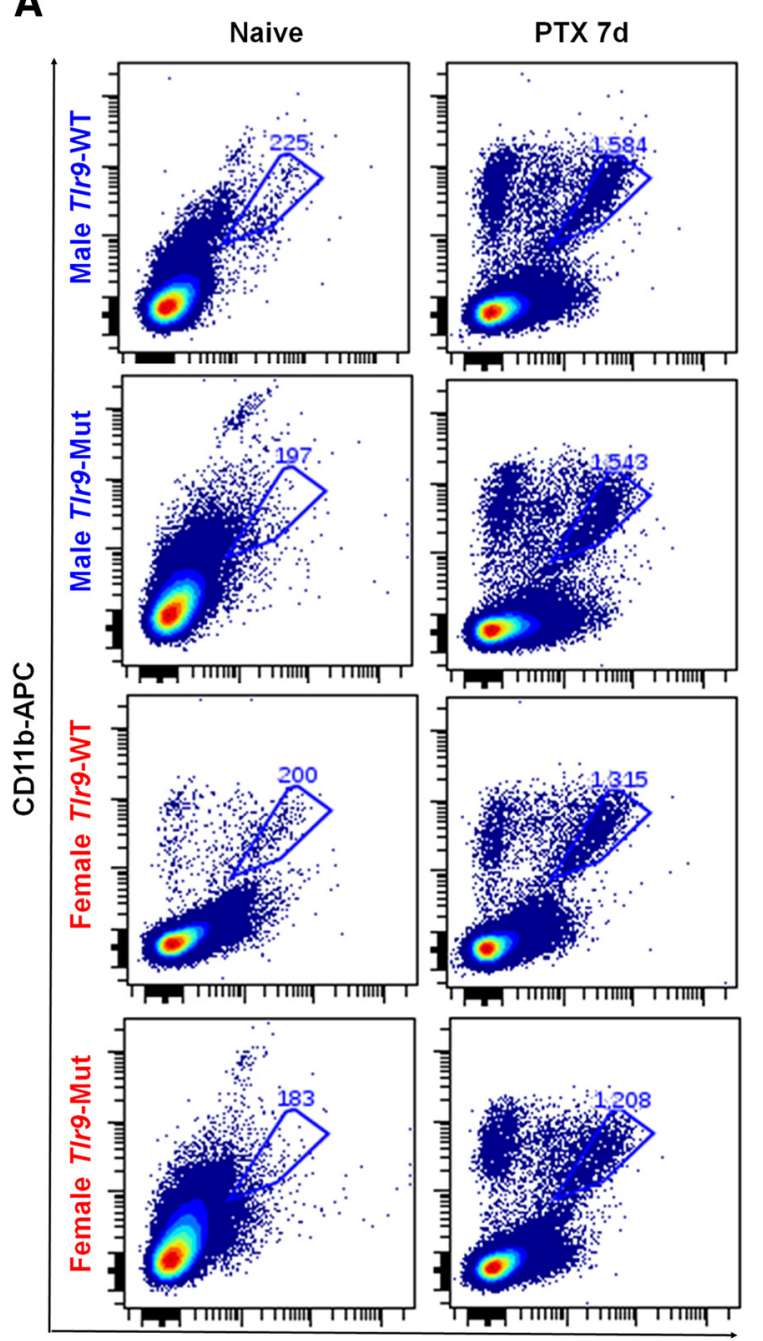

F4/80-FITC
C

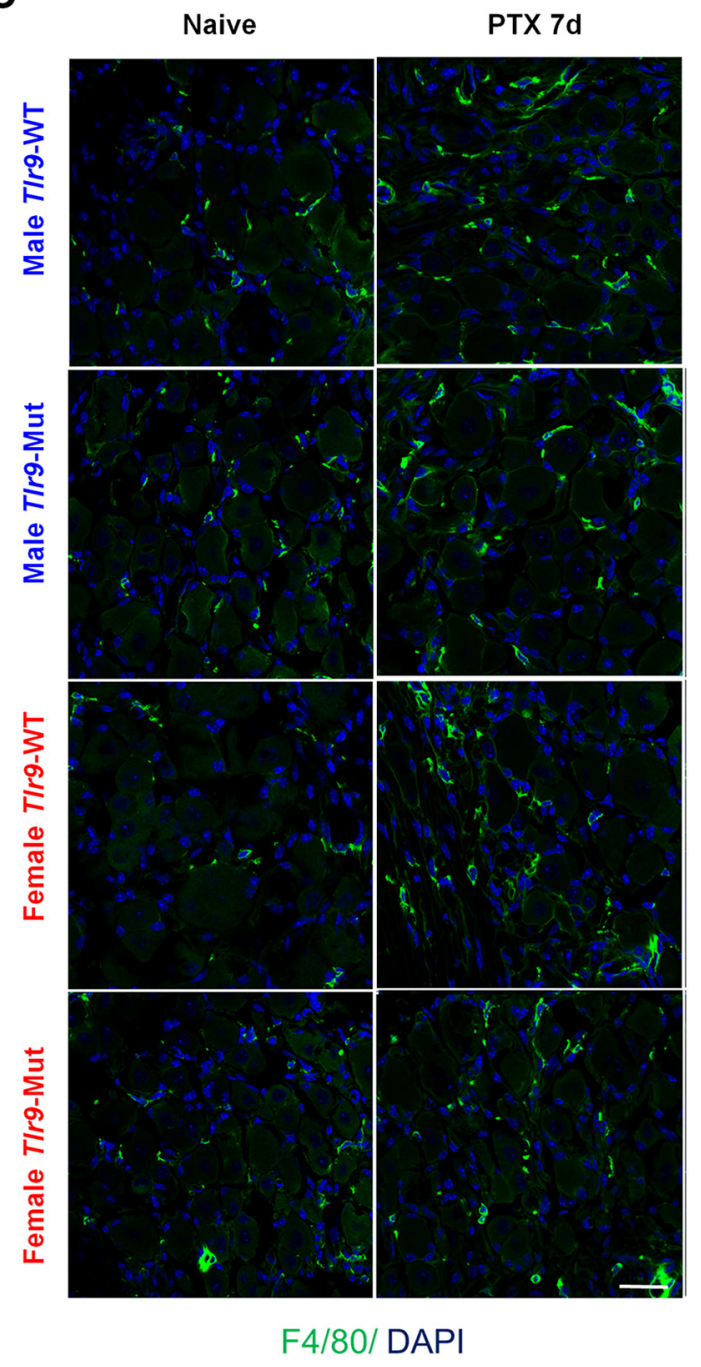

D

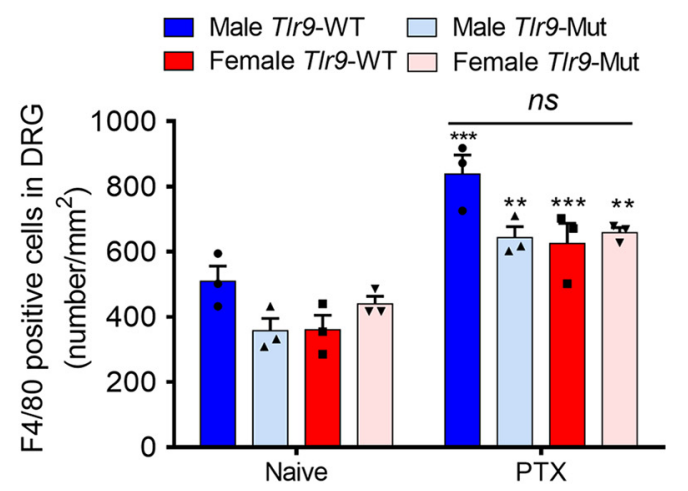

Figure 7. PTX treatment causes comparable macrophage infiltration into DRGs in both sexes of WT and T/r9 mutant mice. $A-D$, FACS analysis showed that the number of F4/80 and CD11bpositive cells increased in DRGs taken from male and female WT and T/r9 mutant mice $7 \mathrm{~d}$ after PTX treatment $(\boldsymbol{A}, \boldsymbol{B} ; n=3-6$ per group). These findings were further confirmed by immunohistochemistry results ( $\boldsymbol{C}, \boldsymbol{D} ; 3$ or $4 \mathrm{DRG}$ sections were counted per mouse, and 3 mice were included per group.). ${ }^{* *} p<0.001,{ }^{* *} p<0.01$, compared with naive group with the same genetic background (two-way ANOVA with Bonferroni's post hoc test). Data are mean \pm SEM. ns, not significant.

Notably, PTX treatment upregulated serum levels of CXCL1 in WT male mice but not in Tlr9 mutant mice (Fig. $10 D ; F_{(1,32)}=$ 16.03, $p<0.05$, two-way ANOVA). We also found that PTX upregulated TNF levels in male mice and upregulated CXCL1 levels in the peritoneal fluid of both sexes, but again these PTXinduced changes did not occur in Tlr9 mutant male mice (Fig.
$10 E, F ; p<0.05$, two-way ANOVA; $F_{(1,40)}=14.21$ in Fig. $10 E$ and $F_{(1,32)}=28.16$ in Fig. 10F). Furthermore, PTX promoted the increase of TNF levels in DRGs of both sexes and CXCL1 levels in DRGs of males, but these changes were again found to be inhibited by $T l r 9$ mutation in male mice (Fig. $10 G, H ; F_{(1,44)}=27.06$ in Fig. $10 G$ and $F_{(1,40)}=13.10$ in Fig. $10 H ; p<0.05$, two-way 
A
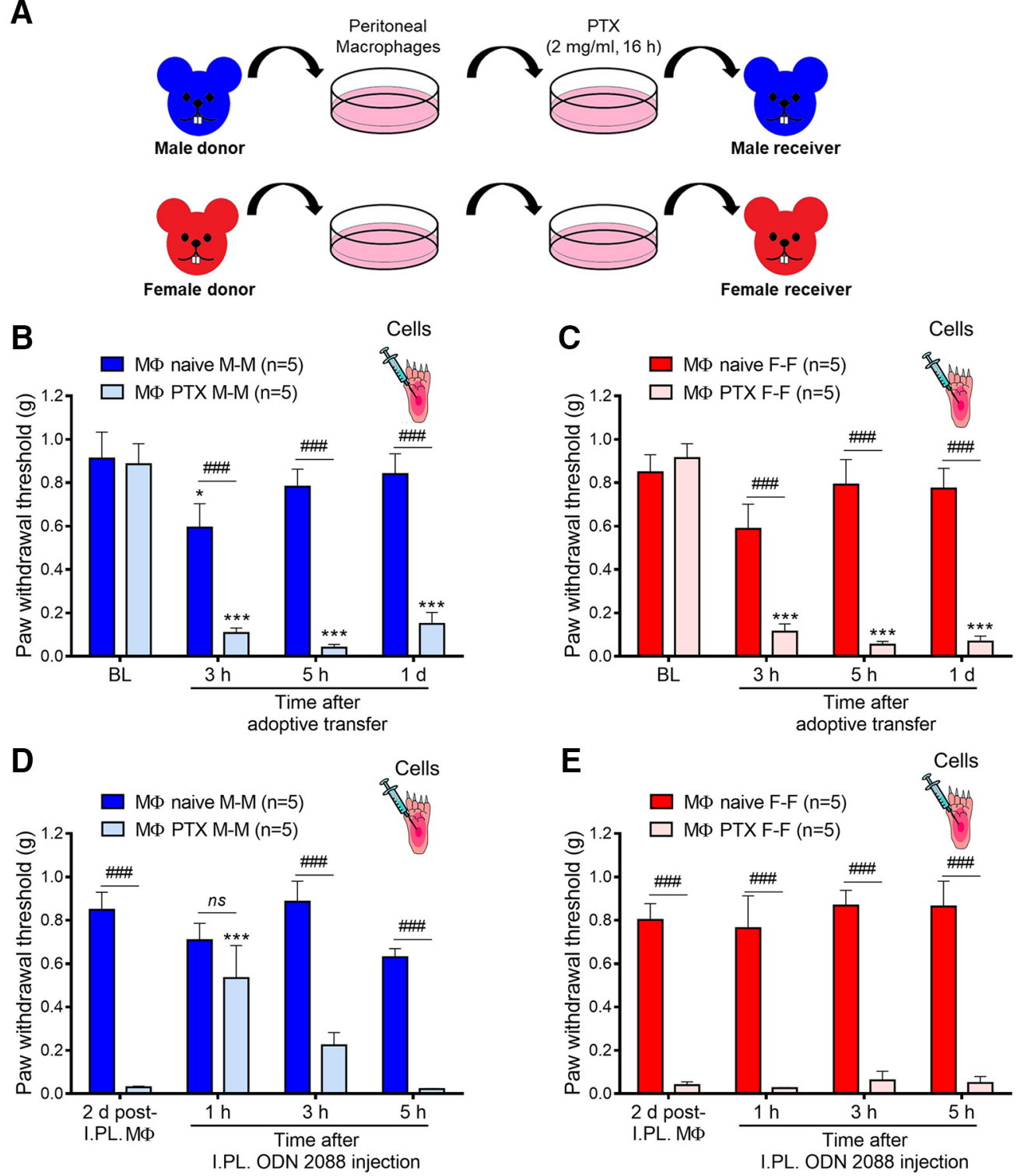

Figure 8. Adoptive transfer of PTX-activated and sex-matched macrophages induces mechanical allodynia in male and female mice. $\boldsymbol{A}$, Schematic of the experimental design. $\boldsymbol{B}$, $\boldsymbol{C}$, Single intraplantar injection of PTX-primed macrophages evoked potent and sustained mechanical allodynia in both male $(\boldsymbol{B})$ and female $(\boldsymbol{C})$ mice. By contrast, injection of WT sex-matched macrophages only produced mild and transient mechanical allodynia in both sexes $(\boldsymbol{B}, \boldsymbol{C}) \cdot \boldsymbol{D}, \boldsymbol{E}$, Intraplantar injection of $10 \mu \mathrm{g}$ of ODN 2088 on postadoptive day 2 increased paw withdrawal threshold in male (D) but not female $(\boldsymbol{E})$ mice. Compared with the baseline of the same group (two-way ANOVA with Bonferroni's post hoc test): ${ }^{* * *} p<0.001 ;{ }^{*} p<0.05$. Compared with naive macrophage group (two-way ANOVA with Bonferroni's post hoc test): ${ }^{\# \#} p<0.001 . n=5$ per group. Data are mean \pm SEM. ns, not significant, M $\Phi$, macrophages.

ANOVA). Together, these results pointed to a male-specific role of TLR9 in the PTX-induced release of TNF and CXCL1 from macrophages and the expression of TNF and CXCL1 in DRGs. These results illustrate the sex-dimorphic regulation of cytokine and chemokine release from macrophages and DRGs following PTX treatment.

\section{The CXCR2 antagonist SB225002 reversed mechanical} allodynia in PTX-treated WT mice of both sexes

The CXCL1/CXCR2 chemokine axis promotes persistent neuropathic pain via central glia-neuron crosstalk (Zhang et al., 2013; Cao et al., 2014; Chen et al., 2014). However, the role of CXCL1/CXCR2 signaling in CIPN remains unclear. Given that CXCL1 levels were elevated in PTX-treated mice, we hypothesized that CXCL1/CXCR2 signaling may contribute to peripheral processing of CIPN. We examined the effects of the
CXCR2 antagonist SB225002 $(20 \mu \mathrm{g})$ on PTX-treated male and female C57BL/6B WT mice on day 3 after PTX injection. The von Frey test results showed that SB225002 reversed PTXinduced mechanical allodynia in mice of both sexes, as indicated by increased paw withdrawal threshold (Fig. 11A,B; $F_{(4,40)}=90.69$ in Fig. $11 A$ and $F_{(4,40)}=116.2$ in Fig. $11 B ; p<$ 0.05 , two-way ANOVA) and decreased paw withdrawal frequency (Fig. 11C,D; Fig. 11C: $F_{(4,40)}=23.98$; Fig. $11 D: F_{(4,40)}$ $=36.12 ; p<0.05$, two-way ANOVA) in comparison with the vehicle control group.

TLR9 antagonism reversed PTX-induced mechanical allodynia in female nude mice

Emerging studies implicate $\mathrm{T}$ cells as a female-specific contributor to chronic pain (Sorge et al., 2015). To address a possible role of T cells in CIPN in female mice, we used nude 
A
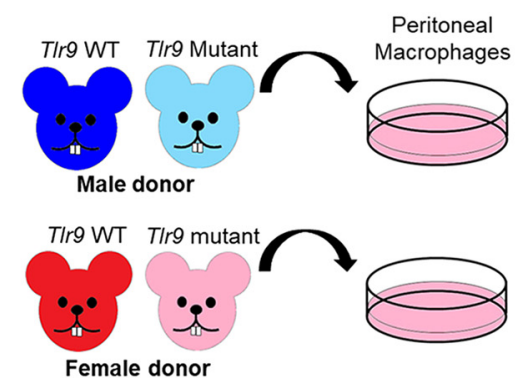

\section{B}
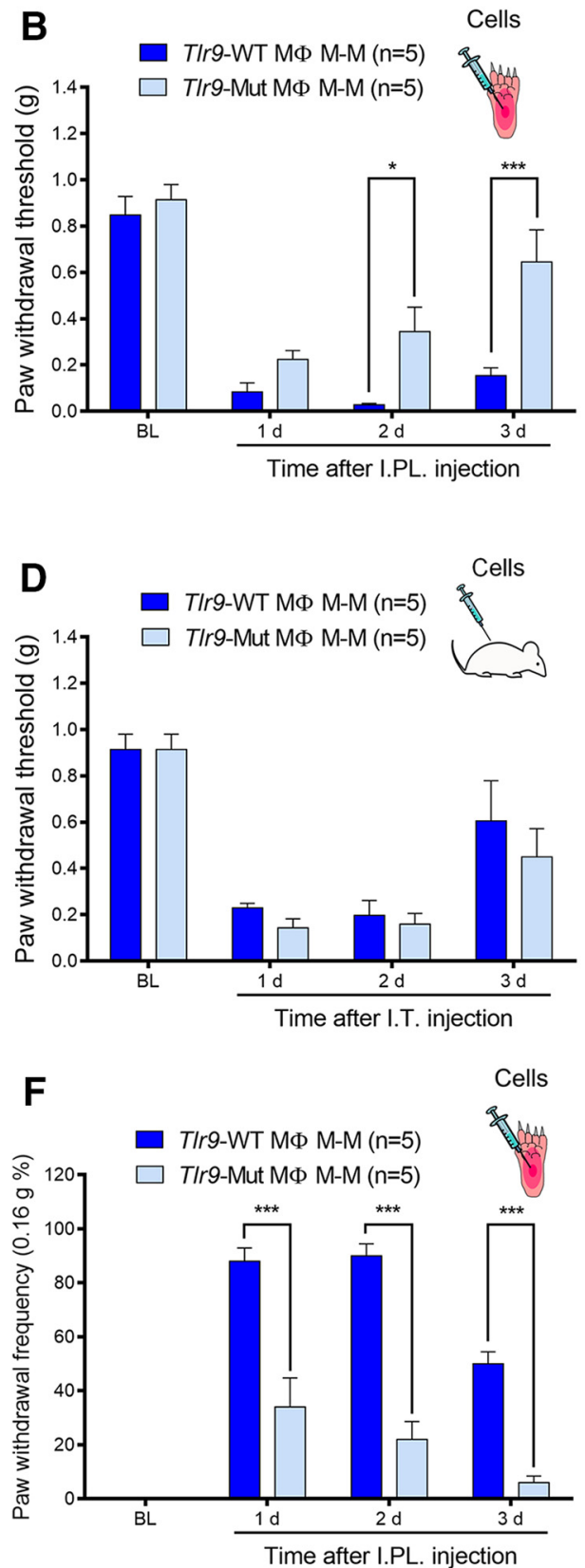

PTX $(2 \mathrm{mg} / \mathrm{ml}, 16 \mathrm{~h})$

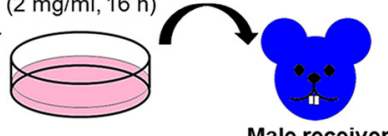

Male receiver

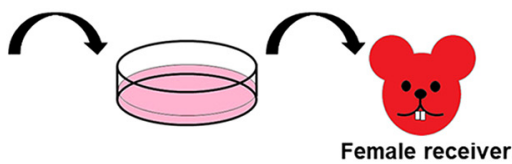

C
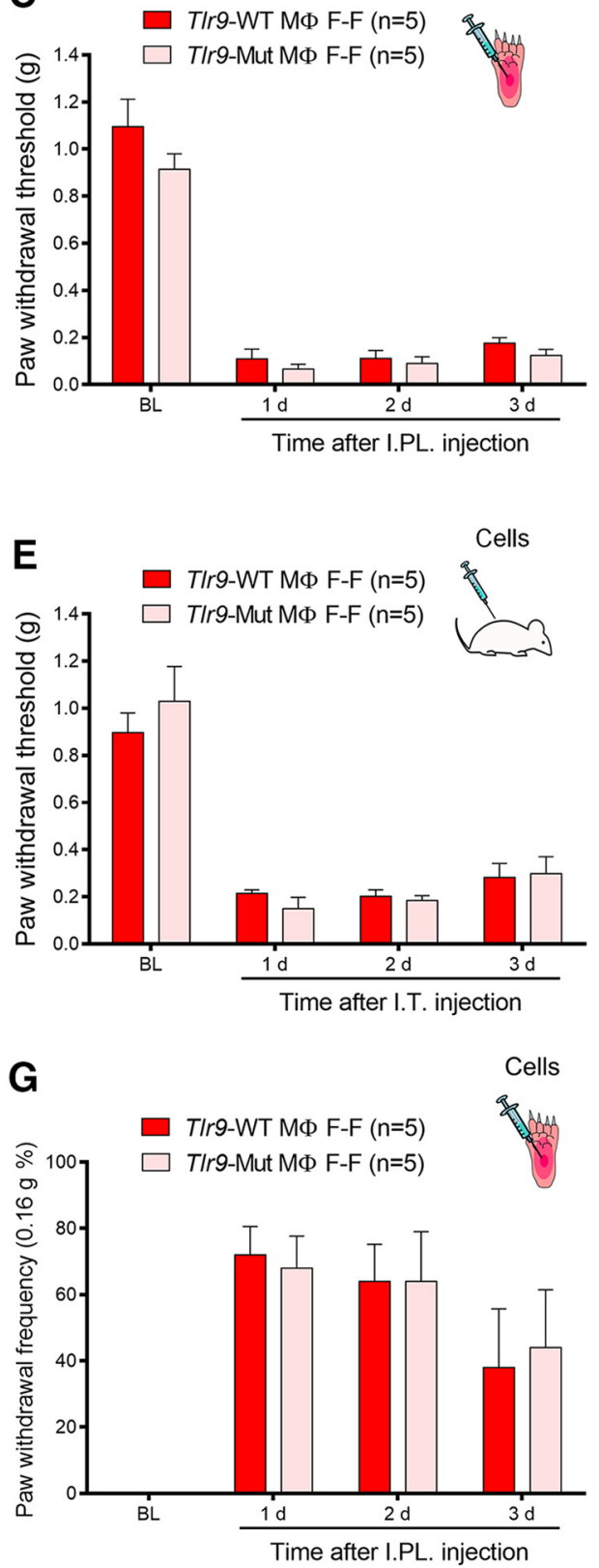

Figure 9. Adoptive transfer of PTX-activated macrophages (MФ) induced TLR9-dependent mechanical allodynia in male mice. $\boldsymbol{A}$, Paradigm of experimental design. $\boldsymbol{B}-\boldsymbol{E}$, Paw withdrawal threshold. B, C, Trr9 mutation alleviated intraplantar PTX-primed macrophage-caused mechanical allodynia in male mice, compared with WT macrophage treatment group (B). However, T/r9 mutation failed to affect intraplantar PTX-primed macrophage-caused pain in female mice ( $\boldsymbol{C}$. Furthermore, T/r9 mutation failed to affect intrathecal PTX-primed macrophage-caused pain in neither male nor female mice $(\boldsymbol{D}, \boldsymbol{E})$. Compared with WT group (two-way ANOVA with Bonferroni's post hoc test): ${ }^{* *} p<0.001 ;{ }^{*} p<0.05 . n=5$ per group. $\boldsymbol{F}, \boldsymbol{G}$, Paw withdrawal frequency. Adoptive transfer of PTX-activated macrophages via intraplantar injection increased paw withdrawal frequency in male, but not female, mice via TLR9. T/r 9 mutation in recipient mice reduced intraplantar PTX-primed macrophage-induced increase in withdrawal frequency in male $(\boldsymbol{F})$ but not female $(\boldsymbol{G})$ C57BL/6B mice. Compared with WT group (two-way ANOVA with Bonferroni's post hoc test): $*^{* * *} p<0.001 . n=5$ per group. Data are mean \pm SEM. 
A

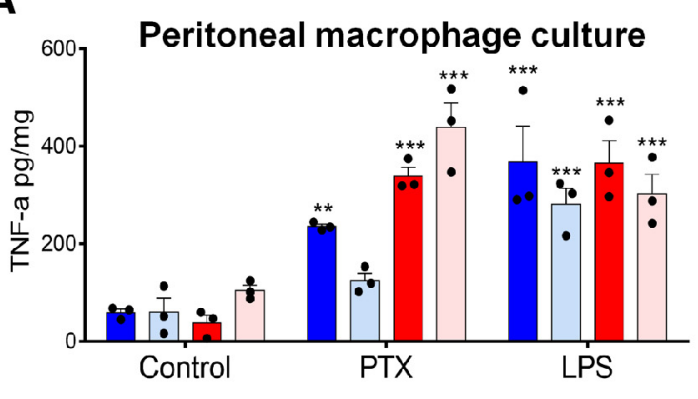

C

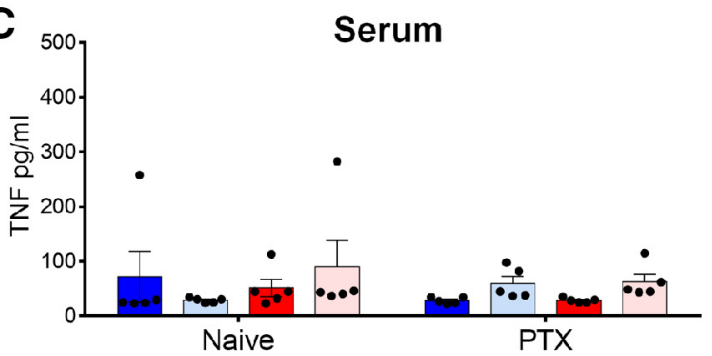

E

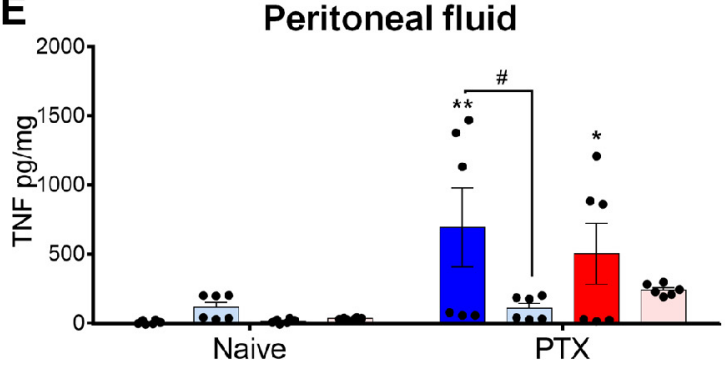

G

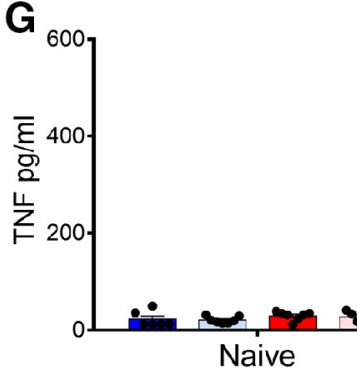

Naive
DRG

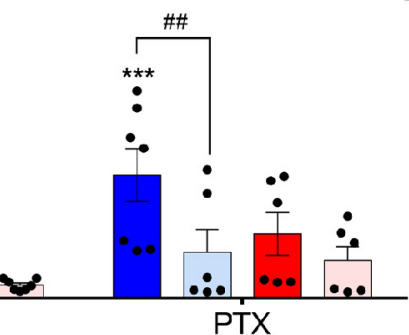

B

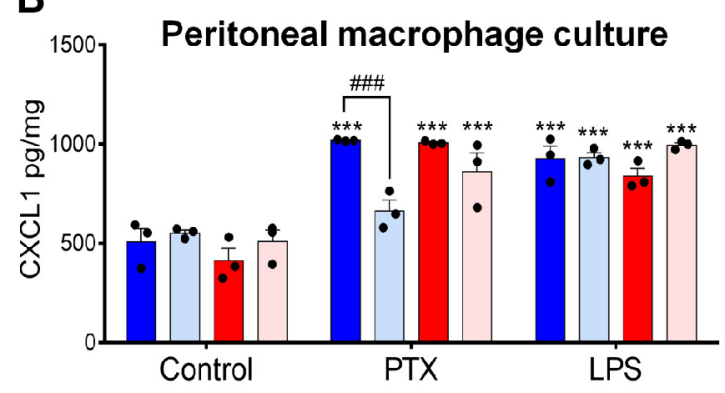

D

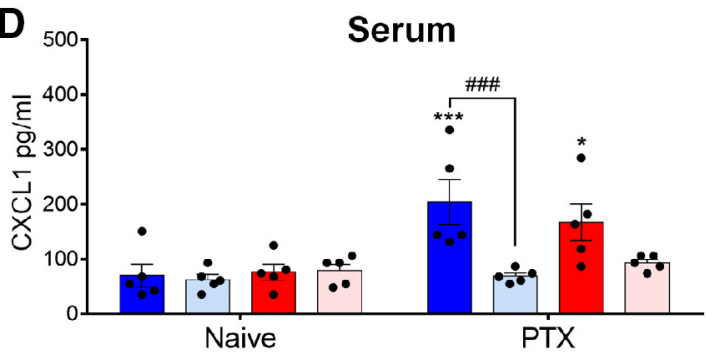

F

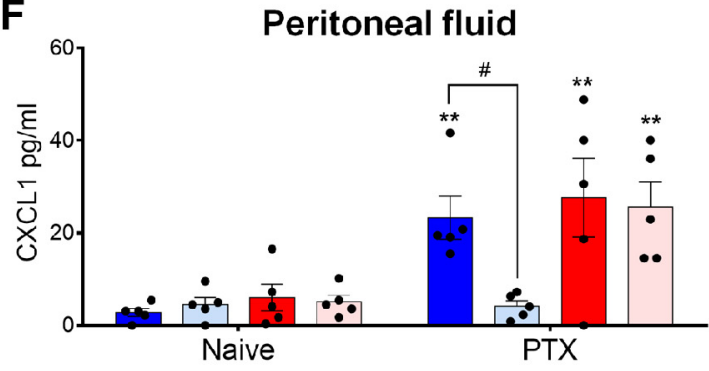

H

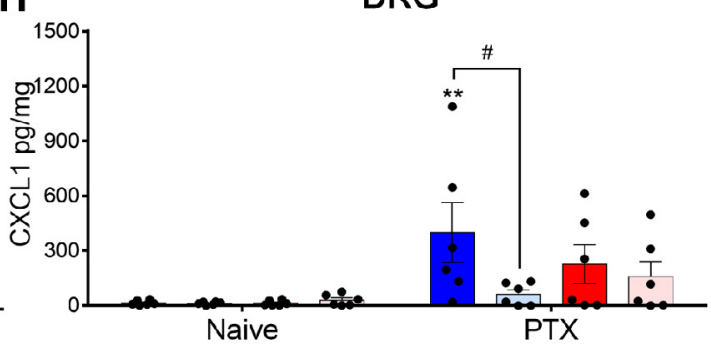

Figure 10. PTX-induced TNF and CXCL1 expression and release are impaired in male TIr9 mutant mice. $\boldsymbol{A}-\boldsymbol{H}$, ELISA testing results of concentrations of TNF and CXCL1 in peritoneal macrophage culture medium $\left(\boldsymbol{A}, \boldsymbol{B} ; n=3\right.$ culture per group, $1 \times 10^{5}$ cells per culture), serum $(\boldsymbol{C}, \boldsymbol{D} ; n=5$ per group, $100 \mu$ l serum per sample), peritoneal fluid $(\boldsymbol{E}, \boldsymbol{F} ; n=5,6 \mathrm{ml}$ per mice), and DRG tissue lysate ( $\boldsymbol{G}, \boldsymbol{H} ; n=5$ per group, 3 DRG tissues collected per mice). Compared with the control or naive group with the same genetic background (two-way ANOVA with Bonferroni's post hoc test): ${ }^{* * *} p<0.001 ;{ }^{* *} p<0.01 ;{ }^{*} p<0.05$. Compared with WT mice group (two-way ANOVA with Bonferroni's post hoc test): \#\#\# $p<0.001 ;{ }^{\# \#} p<0.01 ; "$ \# $<$ 0.05. Data are mean \pm SEM.

mice (NOD.CB17-Prkdc ${ }^{\text {scid }}$ ) with deficiency in T cells and B cells. Notably, PTX was fully capable of evoking mechanical allodynia in nude female mice (Fig. $10 ; F_{(4,40)}=114.7, p<$ 0.001 , two-way ANOVA), suggesting that T cells may not play a major role in the development of CIPN in female mice. Furthermore, PTX-induced mechanical allodynia in female nude mice was reversed by intraplantar injection of the TLR9 antagonist ODN $2088(10 \mu \mathrm{g})$ (Fig. 12; $F_{(4,40)}=114.7, p<$ 0.05, two-way ANOVA). These data indicated that CIPN in female mice may require TLR9 signaling in an immunodeficient background, although TLR9 not be necessary for the development of CIPN in WT female mice with an intact immune system.

\section{Discussion}

We have demonstrated cellular and molecular mechanisms of TLR9 signaling in CIPN, using Tlr9 mutant (deficient) mice of both sexes. Here, we found in male mice, but not in female mice, 
A
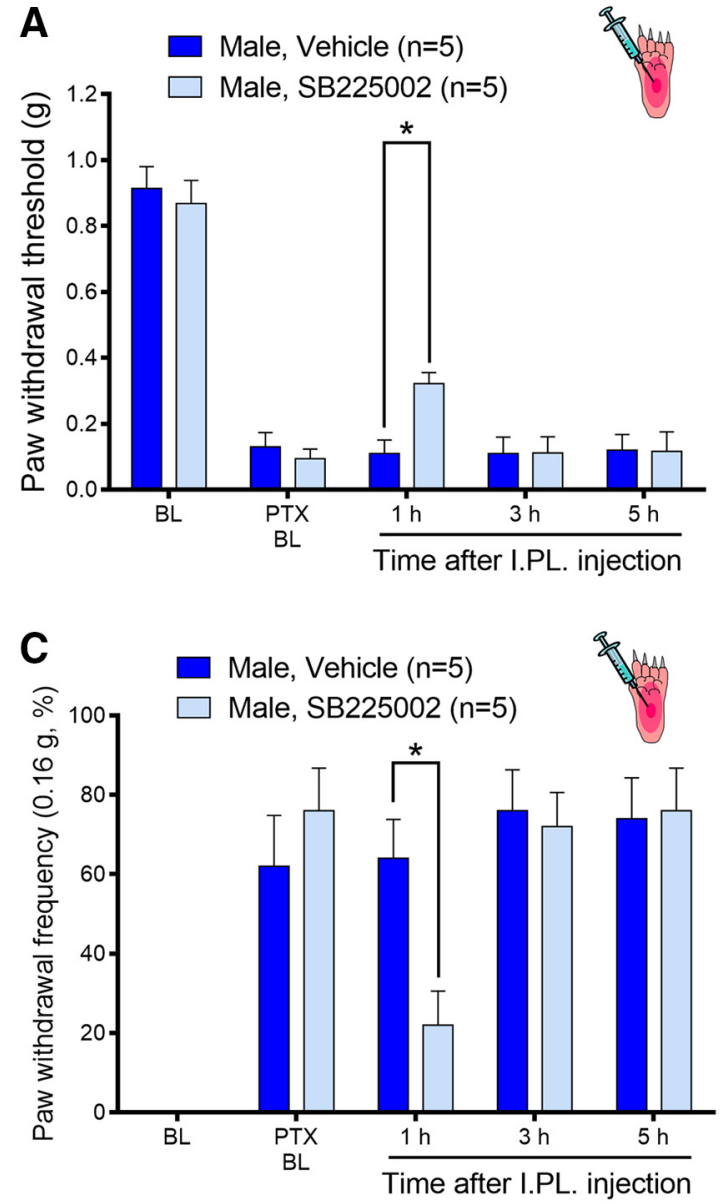

B
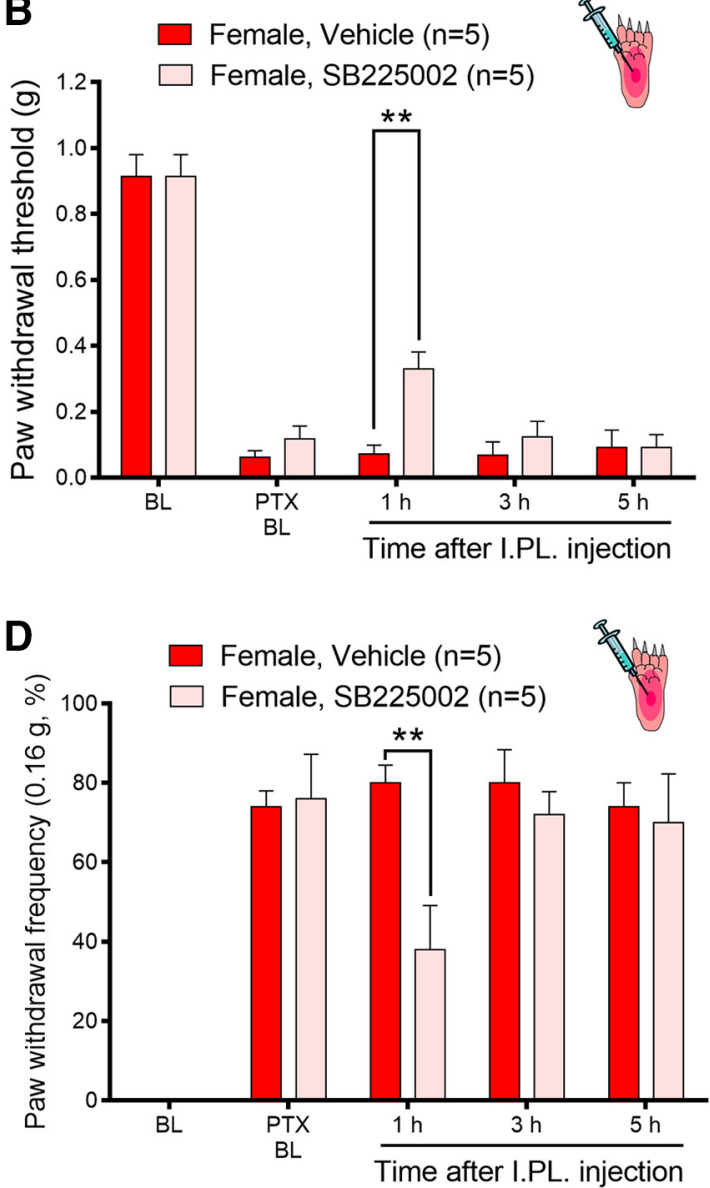

Figure 11. Intraplantar injection of CXCR2 antagonist SB225002 attenuates PTX-induced mechanical allodynia in both sexes. $A, B$, Paw withdrawal threshold. Intraplantar injection of $20 \mu g$ of SB225002 increased paw withdrawal threshold and decreased paw withdrawal frequency in both male $(\boldsymbol{A})$ and female $(\boldsymbol{B})$ mice following PTX treatment (after PTX day 9). Compared with vehicle group (two-way ANOVA with Bonferroni's post hoc test): ${ }^{* *} p<0.01 ;{ }^{*} p<0.05 . n=5$ mice per group. $C, D$, Paw withdrawal frequency. Intraplantar injection of $20 \mu \mathrm{g}$ of $S B 225002$ decreased paw withdrawal frequency in both male $(\boldsymbol{C})$ and female $(\boldsymbol{D})$ mice following PTX treatment (after PTX day 9). Compared with vehicle group (two-way ANOVA with Bonferroni's post hoc test): ${ }^{* *} p<0.01$; ${ }^{*} p<0.05 . n=5$ mice per group. Data are mean \pm SEM.

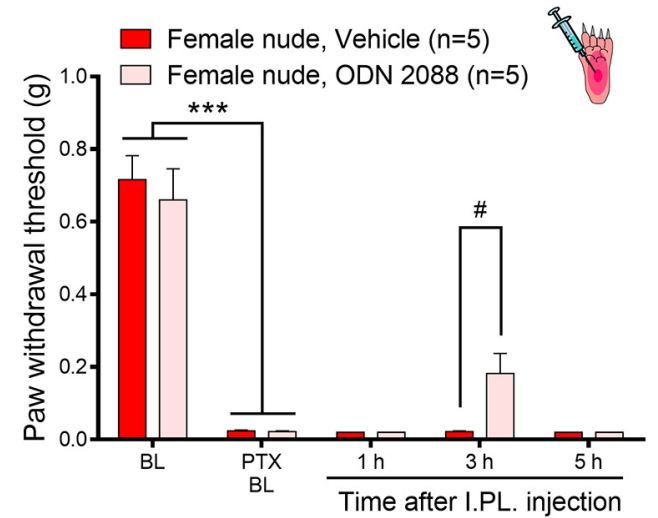

Figure 12. Intraplantar injection of TLR9 antagonist ODN 2088 reverses PTX-induced mechanical allodynia in female nude mice. Intraplantar injection of $10 \mu \mathrm{g}$ ODN 2088 increased paw withdrawal threshold in PTX-treated female nude mice (after PTX day 12). ${ }^{* * *} p<0.05$ compared with BL. $" p<0.05$ compared with vehicle group. Two-way ANOVA with Bonferroni's post hoc test; $n=5$ mice per group. Data are mean \pm SEM.

that Tlr9 mutation attenuated the development of neuropathic pain caused by PTX. Notably, TLR9 antagonist injected intraplantarly alleviated PTX-induced mechanical allodynia only in male WT mice. PTX elicited macrophage infiltration to DRGs in both sexes did not require TLR9. Intriguingly, Tlr9 mutation blunted mechanical allodynia induced by PTX-primed macrophages in males. Moreover, Tlr9 mutation inhibited PTXinduced upregulation of TNF and CXCL1 in macrophage cultures and DRG tissues taken from male mice. Finally, TLR9 antagonism reversed PTX-induced pain in immune-deficient female nude mice. Together, our results showed that TLR9 signaling in macrophages contributes to CIPN in a sex-dimorphic manner.

\section{TLR9 regulates the development of mechanical allodynia in} CIPN in male mice

Increasing evidence suggests that TLRs play a major role in chronic pain via regulation of glial signaling and neuroinflammation (Liu et al., 2012a; Nicotra et al., 2012; Bruno et al., 2018). Neuronal signaling of TLRs, such as TLR3 (Liu et al., 2012b), TLR5 (Xu et al., 2015), TLR7 (Park et al., 2014), TLR8 (Zhang et al., 2018), and MyD88 (Liu et al., 2014, 2016), were also implicated in pain regulation. TLR4 and TLR9 also regulate TRPV1 expression and signaling in DRG and trigeminal neurons (Diogenes et al., 2011; Qi et al., 2011; Li et al., 2015b). Additionally, TLR9 regulates cancer pain and neuropathic pain in female mice (Qi et al., 2011; David et al., 2013). Intrathecal treatment of the TLR9 antagonist ODN 2088 reduced heat hyperalgesia after spinal cord injury in female C57BL/6 mice (David et al., 2013). 
A

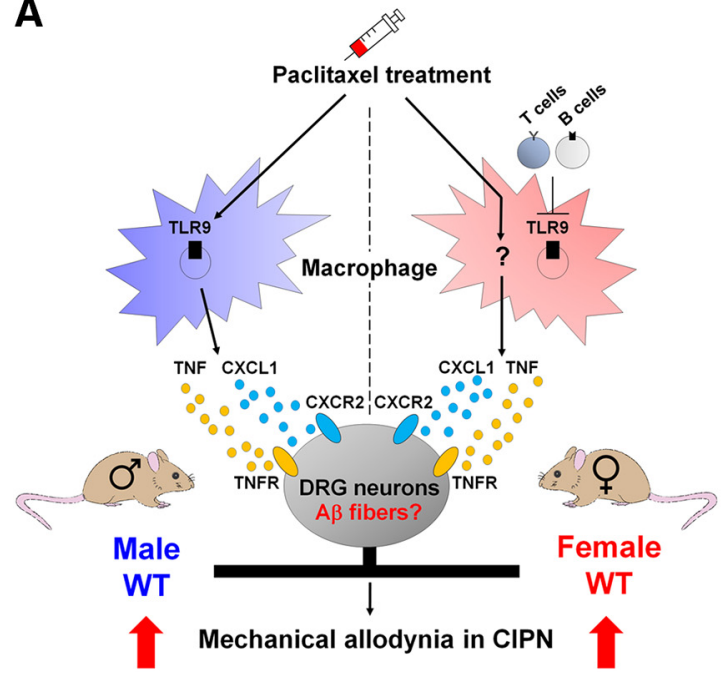

B

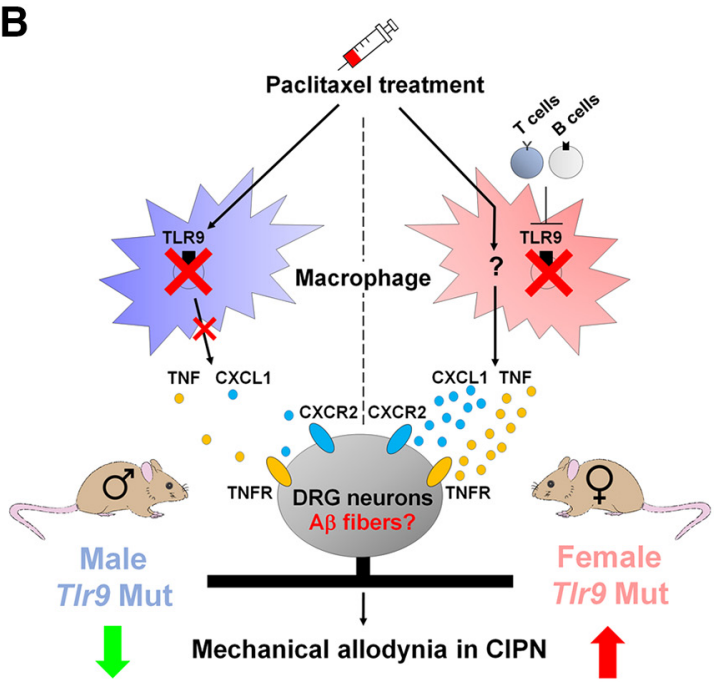

Figure 13. Schematic of working hypothesis for macrophage TLR9 regulation of mechanical allodynia in CIPN in WT and TIr9 mutant mice. A, PTX induces the infiltration and activation of macrophages in DRGs in mice of both sexes. PTX also promotes macrophage release of TNF and CXCL1 in DRGs with subsequent binding to receptors TNFR1/R2 and CXCR2 on sensory neurons, thereby leading to hyperexcitability in nociceptive DRG neurons and driving mechanical allodynia in CIPN. B, Blocking TLR9 attenuates the development of PTX-elicited mechanical allodynia via downregulation of the PTX-induced macrophage release of TNF and CXCL1 only in male, but not female, mice. Additionally, female mice deficient in T and B cells may switch to using TLR9 signaling in CIPN.

Systemic ODN 2088 treatment also reduced heat hyperalgesia in tumor-bearing female Swiss Webster mice (Qi et al., 2011). However, mechanical hypersensitivity, such as mechanical hyperalgesia and mechanical allodynia, which are cardinal features of chronic pain (Alessandri-Haber et al., 2009; Xu et al., 2015), was not tested in these two studies. It is important to note that chemotherapy, such as PTX treatment, produces mechanical and cold allodynia but not thermal hyperalgesia in mice (Smith et al., 2004). Our data showed that a single PTX injection $(6 \mathrm{mg} / \mathrm{kg})$ elicited marked mechanical allodynia and cold allodynia in both sexes, and mechanical allodynia resolved within 4 weeks in male mice but not in female mice. Thus, it is reasonable to postulate that TLR9 may regulate different pain modalities (heat, cold, and mechanical) in different pain models and different sexes.

Our results provided several lines of evidence to support a critical role in CIPN for TLR9 signaling in a pain modality and sex-dependent manner via peripheral and central regulatory mechanisms. First, Tlr9 mutation resulted in delayed development of PTX-induced mechanical allodynia in male mice but not in female mice. PTX-induced cold allodynia, in contrast, was not affected by Tlr9 mutation (Fig. 5), suggesting that mechanical allodynia is the major pain modality demonstrating TLR9mediated sex dimorphism. Second, in agreement with the result from Tlr9 mutant mice, pharmacological inhibition of TLR9 by intraplantar or intrathecal injection of ODN 2088 reduced mechanical allodynia in male, but not female, mice (Fig. 6). This finding also indicated the involvement of TLR9 at both spinal cord and peripheral levels. Furthermore, intraplantar or intrathecal injection of the TLR9 agonist CPG ODN 1826 was sufficient to induce mechanical allodynia in naive mice of both sexes (Fig. 2).

\section{Macrophage mechanisms by which TLR9 regulates inflammation and CIPN in males}

TLR9 may regulate pain via neuronal, glial, and immune mechanisms. For example, TLR9 promotes heat hyperalgesia in cancer pain via regulation of TRPV1 expression in sensory neurons (Qi et al., 2011). Intrathecal TLR9 agonist ODN 1826 increased TNF and CXCL1 transcript levels in the spinal cord of naive animals
(David et al., 2013). Furthermore, spinal cord injury-induced infiltration and activation of immune and glial cells, including $\mathrm{CD}_{4}{ }^{+}$monocytes, $\mathrm{CD} 11 \mathrm{~b}^{+}$macrophages and microglia, and $\mathrm{CD}^{+}{ }^{+} \mathrm{T}$ cells, are reduced by the TLR9 antagonist ODN 2088 (David et al., 2013). Our findings demonstrate that macrophage TLR9 signaling drives mechanical allodynia in CIPN in males.

First, our results demonstrate that TRPV1 and C-fibers are not required for TLR9-mediated mechanical allodynia, as ODN 1826-induced mechanical allodynia was unaltered in Trpv1 KO mice and ablation of C-fibers with resiniferatoxin failed to block ODN 1826-induced mechanical allodynia. Notably, C-fibers and nociceptors may not be required to generate chemotherapyinduced mechanical allodynia (Minett et al., 2014; Xu et al., 2015), and mechanical allodynia from CIPN is mediated by TLR5-expressing A $\beta$ fibers of DRG neurons (Xu et al., 2015). We postulate that activation of TLR9 in male macrophages results in the release of proinflammatory cytokines and chemokines that activate $\mathrm{A} \beta$ fibers, which then drive CIPN mechanical allodynia in male mice (Fig. 13).

Second, our data show that PTX $(2 \mu \mathrm{g} / \mathrm{ml}, 16 \mathrm{~h})$ can directly act on male and female macrophages in vitro to release TNF and CXCL1 into culture medium. Intriguingly, TLR9 signaling differences between male and female macrophages were preserved in vitro as Tlr9 mutation abrogated the PTX-induced release of TNF and CXCL1 levels from male macrophages but not from female macrophages (Fig. 10A,B). Consistently, in vivo results revealed TLR9-mediated upregulation of TNF and CXCL1 in peritoneal fluid and upregulation of CXCL1 in serum collected from male mice receiving PTX treatment (Fig. 10C-F).

Third, we found differences between male and female mice for macrophage signaling (e.g., TLR9, TNF, CXCL1) but not for macrophage infiltration into DRGs. FACS analysis (CD11b/F4/ $80)$ and immunohistochemistry (F4/80) demonstrated increases in macrophage infiltration into DRGs in both WT and Tlr9 mutant mice of both sexes after chemotherapy (Fig. 7). By contrast, chemotherapy caused TLR9-dependent increase of TNF and CXCL1 expression in male DRGs (Fig. 10G,H). These findings with regard to macrophage signaling and infiltration add an ad- 
ditional layer to understanding neuroimmune signaling in chronic pain upon previous studies that revealed distinct expression of microglial signal molecules, such as P-p38, P2X4, and BDNF, in different sexes following nerve injury (Sorge et al., 2015; Taves et al., 2016; Lopes et al., 2017; Mapplebeck et al., 2018).

Fourth, adoptive transfer of PTX-primed macrophages into WT naive mice produced mechanical allodynia in a TLR9dependent manner in male mice (Figs. 8, 9). TLR9 is also required for the maintenance of mechanical allodynia, as intraplantar and intrathecal inhibition of TLR9 via ODN 2088 reversed PTXevoked mechanical allodynia. TLR9 antagonist treatment may also affect macrophages in DRGs, as intrathecal administration in rodents is known to affect the DRG in addition to spinal cord (Kawasaki et al., 2008; Alessandri-Haber et al., 2009). Given the limited role of spinal microglia in CIPN (Zhang et al., 2012; Luo et al., 2018), intrathecal TLR9 antagonist treatment may target TLR9 in DRG macrophages for CIPN relief in male mice.

Finally, the downstream mechanisms of macrophage activation and neuroimmune interaction via TNF and CXCL1 signaling are illustrated in Figure 13. TNF and CXCL1 released from macrophages can bind to their receptors on sensory neurons (TNFR1/R2 and CXCR2) to elicit mechanical allodynia in CIPN. TNF/TNFR and CXCL1/CXCR2 signaling may promote neuronmacrophage crosstalk in CIPN. Subcutaneous and epineural injection of TNF has been shown to induce mechanical allodynia, and TNF induces $\mathrm{A} \beta$ fiber discharge in vitro, in addition to its known effects on C-fibers (Schäfers et al., 2003; Sommer and Kress, 2004; Constantin et al., 2008). Notably, we did not see sex dimorphism in neuronal signaling of cytokine/chemokine receptors, as treatment with CXCR2 antagonist was effective in reducing PTX-induced mechanical allodynia in both sexes (Fig. 11).

\section{Concluding remarks and future directions}

Our study identified TLR9 signaling in macrophages as a new sex-dimorphic biomarker that regulates chemotherapy-induced mechanical allodynia in male mice via neuron-macrophage interactions (Fig. 13). However, clinical data show that women are more likely to suffer from pathological pain (Bartley and Fillingim, 2013). Thus, future studies in pain research will need to specifically address the mechanisms of pain in females to increase our understanding of pain and enable the development of more precise and effective therapies for chronic pain. It is important to point out that sex dimorphism in pain may vary among different pain modalities (e.g., mechanical vs thermal pain) and pain states. For example, spinal cord microglia contribute to bone cancer pain in female rats bearing breast cancer (Yang et al., 2015).

Although T-cell signaling in females may play a dominant role in neuropathic pain after nerve injury (Sorge et al., 2015), our results show that, in female nude mice with $\mathrm{T}$-cell and $\mathrm{B}$-cell deficiency, development of mechanical allodynia after PTX treatment was unaltered. Our results further show that female animals switch to a TLR9-dependent pathway in CIPN under this immune deficiency condition (Fig. 12). This suggests that crosstalk between immune cells may contribute to sex dimorphism in CIPN, and additionally, females may switch or revert back to male-like neuroimmune signaling pathways, including macrophage signaling. Our results do not rule out an important role of $\mathrm{T}$ cells in CIPN in WT mice (Krukowski et al., 2016), as there could be developmental compensations in these immunedeficient mice.

Finally, macrophages may play different and even opposing roles in pain regulation by producing context-dependent proinflammatory, anti-inflammatory, and proresolution mediators (Ji et al., 2016). In addition to promoting neuropathic pain development (Montague et al., 2018), recent studies also demonstrate an important role of macrophages in the resolution of pathological pain (Bang et al., 2018). Future studies are needed to examine the cellular mechanisms, including those involving macrophages and T cells (Krukowski et al., 2016), in sex dimorphism during the resolution of pain.

\section{References}

Akira S, Uematsu S, Takeuchi O (2006) Pathogen recognition and innate immunity. Cell 124:783-801.

Alessandri-Haber N, Dina OA, Chen X, Levine JD (2009) TRPC1 and TRPC6 channels cooperate with TRPV4 to mediate mechanical hyperalgesia and nociceptor sensitization. J Neurosci 29:6217-6228.

Bang S, Xie YK, Zhang ZJ, Wang Z, Xu ZZ, Ji RR (2018) GPR37 regulates macrophage phagocytosis and resolution of inflammatory pain. J Clin Invest 128:3568-3582.

Bartley EJ, Fillingim RB (2013) Sex differences in pain: a brief review of clinical and experimental findings. Br J Anaesth 111:52-58.

Berta T, Qadri YJ, Chen G, Ji RR (2016) Microglial signaling in chronic pain with a special focus on caspase 6, p38 MAP kinase, and sex dependence. J Dent Res 95:1124-1131.

Brennan TV, Lin L, Brandstadter JD, Rendell VR, Dredge K, Huang X, Yang Y (2016) Heparan sulfate mimetic PG545-mediated antilymphoma effects require TLR9-dependent NK cell activation. J Clin Invest 126:207-219.

Bruno K, Woller SA, Miller YI, Yaksh TL, Wallace M, Beaton G, Chakravarthy K (2018) Targeting Toll-like receptor-4 (TLR4): an emerging therapeutic target for persistent pain states. Pain 159:1908-1915.

Cao DL, Zhang ZJ, Xie RG, Jiang BC, Ji RR, Gao YJ (2014) Chemokine CXCL1 enhances inflammatory pain and increases NMDA receptor activity and COX-2 expression in spinal cord neurons via activation of CXCR2. Exp Neurol 261:328-336.

Cata JP, Weng HR, Burton AW, Villareal H, Giralt S, Dougherty PM (2007) Quantitative sensory findings in patients with bortezomib-induced pain. J Pain 8:296-306.

Cavaletti G, Bogliun G, Marzorati L, Zincone A, Marzola M, Colombo N, Tredici G (1995) Peripheral neurotoxicity of taxol in patients previously treated with cisplatin. Cancer 75:1141-1150.

Chen G, Park CK, Xie RG, Berta T, Nedergaard M, Ji RR (2014) Connexin-43 induces chemokine release from spinal cord astrocytes to maintain late-phase neuropathic pain in mice. Brain 137:2193-2209.

Chen G, Park CK, Xie RG, Ji RR (2015) Intrathecal bone marrow stromal cells inhibit neuropathic pain via TGF-beta secretion. J Clin Invest 125: 3226-3240.

Chen G, Luo X, Qadri MY, Berta T, Ji RR (2018) Sex-dependent glial signaling in pathological pain: distinct roles of spinal microglia and astrocytes. Neurosci Bull 34:98-108.

Christianson CA, Dumlao DS, Stokes JA, Dennis EA, Svensson CI, Corr M, Yaksh TL (2011) Spinal TLR4 mediates the transition to a persistent mechanical hypersensitivity after the resolution of inflammation in serum-transferred arthritis. Pain 152:2881-2891.

Constantin CE, Mair N, Sailer CA, Andratsch M, Xu ZZ, Blumer MJ, Scherbakov N, Davis JB, Bluethmann H, Ji RR, Kress M (2008) Endogenous tumor necrosis factor alpha (TNFalpha) requires TNF receptor type 2 to generate heat hyperalgesia in a mouse cancer model. J Neurosci 28:50725081.

Das N, Dewan V, Grace PM, Gunn RJ, Tamura R, Tzarum N, Watkins LR, Wilson IA, Yin H (2016) HMGB1 activates proinflammatory signaling via TLR5 leading to allodynia. Cell Rep 17:1128-1140.

David BT, Ratnayake A, Amarante MA, Reddy NP, Dong W, Sampath S, Heary RF, Elkabes S (2013) A Toll-like receptor 9 antagonist reduces pain hypersensitivity and the inflammatory response in spinal cord injury. Neurobiol Dis 54:194-205.

Diogenes A, Ferraz CC, Akopian AN, Henry MA, Hargreaves KM (2011) LPS sensitizes TRPV1 via activation of TLR4 in trigeminal sensory neurons. J Dent Res 90:759-764.

Forsyth PA, Balmaceda C, Peterson K, Seidman AD, Brasher P, DeAngelis LM (1997) Prospective study of paclitaxel-induced peripheral neuropathy with quantitative sensory testing. J Neurooncol 35:47-53. 
Gutierrez S, Hayashida K, Eisenach JC (2013) The puerperium alters spinal cord plasticity following peripheral nerve injury. Neuroscience 228: 301-308.

Han Q, Kim YH, Wang X, Liu D, Zhang ZJ, Bey AL, Lay M, Chang W, Berta T, Zhang Y, Jiang YH, Ji RR (2016) SHANK3 deficiency impairs heat hyperalgesia and TRPV1 signaling in primary sensory neurons. Neuron 92:1279-1293.

Huh Y, Ji RR, Chen G (2017) Neuroinflammation, bone marrow stem cells, and chronic pain. Front Immunol 8:1014.

Inyang KE, Szabo-Pardi T, Wentworth E, McDougal TA, Dussor G, Burton MD, Price TJ (2019) The antidiabetic drug metformin prevents and reverses neuropathic pain and spinal cord microglial activation in male but not female mice. Pharmacol Res 139:1-16.

Ji RR, Chamessian A, Zhang YQ (2016) Pain regulation by non-neuronal cells and inflammation. Science 354:572-577.

Kawasaki Y, Xu ZZ, Wang X, Park JY, Zhuang ZY, Tan PH, Gao YJ, Roy K, Corfas G, Lo EH, Ji RR (2008) Distinct roles of matrix metalloproteases in the early- and late-phase development of neuropathic pain. Nat Med 14:331-336.

Kim D, Kim MA, Cho IH, Kim MS, Lee S, Jo EK, Choi SY, Park K, Kim JS, Akira S, Na HS, Oh SB, Lee SJ (2007) A critical role of Toll-like receptor 2 in nerve injury-induced spinal cord glial cell activation and pain hypersensitivity. J Biol Chem 282:14975-14983.

Krieg AM (2002) CpG motifs in bacterial DNA and their immune effects. Annu Rev Immunol 20:709-760.

Krieg AM (2006) Therapeutic potential of Toll-like receptor 9 activation. Nat Rev Drug Discov 5:471-484.

Krukowski K, Eijkelkamp N, Laumet G, Hack CE, Li Y, Dougherty PM, Heijnen CJ, Kavelaars A (2016) $\mathrm{CD}^{+}{ }^{+} \mathrm{T}$ cells and endogenous IL-10 are required for resolution of chemotherapy-induced neuropathic pain. J Neurosci 36:11074-11083.

Li Y, Zhang H, Zhang H, Kosturakis AK, Jawad AB, Dougherty PM (2014) Toll-like receptor 4 signaling contributes to paclitaxel-induced peripheral neuropathy. J Pain 15:712-725.

Li Y, Zhang H, Kosturakis AK, Cassidy RM, Zhang H, Kennamer-Chapman RM, Jawad AB, Colomand CM, Harrison DS, Dougherty PM (2015a) MAPK signaling downstream to TLR4 contributes to paclitaxel-induced peripheral neuropathy. Brain Behav Immun 49:255-266.

Li Y, Adamek P, Zhang H, Tatsui CE, Rhines LD, Mrozkova P, Li Q, Kosturakis AK, Cassidy RM, Harrison DS, Cata JP, Sapire K, Zhang H, KennamerChapman RM, Jawad AB, Ghetti A, Yan J, Palecek J, Dougherty PM (2015b) The cancer chemotherapeutic paclitaxel increases human and rodent sensory neuron responses to TRPV1 by activation of TLR4. J Neurosci 35:13487-13500.

Liu CC, Lu N, Cui Y, Yang T, Zhao ZQ, Xin WJ, Liu XG (2010) Prevention of paclitaxel-induced allodynia by minocycline: effect on loss of peripheral nerve fibers and infiltration of macrophages in rats. Mol Pain 6:76.

Liu T, Gao YJ, Ji RR (2012a) Emerging role of Toll-like receptors in the control of pain and itch. Neurosci Bull 28:131-144.

Liu T, Berta T, Xu ZZ, Park CK, Zhang L, Lü N, Liu Q, Liu Y, Gao YJ, Liu YC, Ma Q, Dong X, Ji RR (2012b) TLR3 deficiency impairs spinal cord synaptic transmission, central sensitization, and pruritus in mice. J Clin Invest 122:2195-2207.

Liu XJ, Zhang Y, Liu T, Xu ZZ, Park CK, Berta T, Jiang D, Ji RR (2014) Nociceptive neurons regulate innate and adaptive immunity and neuropathic pain through MyD88 adapter. Cell Res 24:1374-1377.

Liu XJ, Liu T, Chen G, Wang B, Yu XL, Yin C, Ji RR (2016) TLR signaling adaptor protein MyD88 in primary sensory neurons contributes to persistent inflammatory and neuropathic pain and neuroinflammation. Sci Rep 6:28188.

Lopes DM, Malek N, Edye M, Jager SB, McMurray S, McMahon SB, Denk F (2017) Sex differences in peripheral not central immune responses to pain-inducing injury. Sci Rep 7:16460.

Luo X, Fitzsimmons B, Mohan A, Zhang L, Terrando N, Kordasiewicz H, Ji RR (2018) Intrathecal administration of antisense oligonucleotide against p38alpha but not p38beta MAP kinase isoform reduces neuropathic and postoperative pain and TLR4-induced pain in male mice. Brain Behav Immun 72:34-44.

Makker PG, Duffy SS, Lees JG, Perera CJ, Tonkin RS, Butovsky O, Park SB, Goldstein D, Moalem-Taylor G (2017) Characterisation of immune and neuroinflammatory changes associated with chemotherapy-induced peripheral neuropathy. PLoS One 12:e0170814.
Mapplebeck JC, Dalgarno R, Tu Y, Moriarty O, Beggs S, Kwok CH, Halievski K, Assi S, Mogil JS, Trang T, Salter MW (2018) Microglial P2X4Revoked pain hypersensitivity is sexually dimorphic in rats. Pain 159:1752-1763.

Minett MS, Falk S, Santana-Varela S, Bogdanov YD, Nassar MA, Heegaard AM, Wood JN (2014) Pain without nociceptors? Nav1.7-independent pain mechanisms. Cell Rep 6:301-312.

Mogil JS (2012) Sex differences in pain and pain inhibition: multiple explanations of a controversial phenomenon. Nat Rev Neurosci 13:859-866.

Montague K, Malcangio M (2017) The therapeutic potential of monocyte/ macrophage manipulation in the treatment of chemotherapy-induced painful neuropathy. Front Mol Neurosci 10:397.

Montague K, Simeoli R, Valente J, Malcangio M (2018) A novel interaction between CX3CR1 and CCR2 signalling in monocytes constitutes an underlying mechanism for persistent vincristine-induced pain. J Neuroinflammation 15:101.

Nicotra L, Loram LC, Watkins LR, Hutchinson MR (2012) Toll-like receptors in chronic pain. Exp Neurol 234:316-329.

Old EA, Nadkarni S, Grist J, Gentry C, Bevan S, Kim KW, Mogg AJ, Perretti M, Malcangio M (2014) Monocytes expressing CX3CR1 orchestrate the development of vincristine-induced pain. J Clin Invest 124:2023-2036.

Park CK, Xu ZZ, Berta T, Han Q, Chen G, Liu XJ, Ji RR (2014) Extracellular microRNAs activate nociceptor neurons to elicit pain via TLR7 and TRPA1. Neuron 82:47-54.

Peters CM, Jimenez-Andrade JM, Jonas BM, Sevcik MA, Koewler NJ, Ghilardi JR, Wong GY, Mantyh PW (2007) Intravenous paclitaxel administration in the rat induces a peripheral sensory neuropathy characterized by macrophage infiltration and injury to sensory neurons and their supporting cells. Exp Neurol 203:42-54.

Postma TJ, Benard BA, Huijgens PC, Ossenkoppele GJ, Heimans JJ (1993) Long-term effects of vincristine on the peripheral nervous system. J Neurooncol 15:23-27.

Pusztai L, Mendoza TR, Reuben JM, Martinez MM, Willey JS, Lara J, Syed A, Fritsche HA, Bruera E, Booser D, Valero V, Arun B, Ibrahim N, Rivera E, Royce M, Cleeland CS, Hortobagyi GN (2004) Changes in plasma levels of inflammatory cytokines in response to paclitaxel chemotherapy. Cytokine 25:94-102.

Qi J, Buzas K, Fan H, Cohen JI, Wang K, Mont E, Klinman D, Oppenheim JJ, Howard OM (2011) Painful pathways induced by TLR stimulation of dorsal root ganglion neurons. J Immunol 186:6417-6426.

Rosen S, Ham B, Mogil JS (2017) Sex differences in neuroimmunity and pain. J Neurosci Res 95:500-508.

Schäfers M, Lee DH, Brors D, Yaksh TL, Sorkin LS (2003) Increased sensitivity of injured and adjacent uninjured rat primary sensory neurons to exogenous tumor necrosis factor-alpha after spinal nerve ligation. J Neurosci 23:3028-3038.

Seretny M, Currie GL, Sena ES, Ramnarine S, Grant R, MacLeod MR, Colvin LA, Fallon M (2014) Incidence, prevalence, and predictors of chemotherapy-induced peripheral neuropathy: a systematic review and meta-analysis. Pain 155:2461-2470.

Smith SB, Crager SE, Mogil JS (2004) Paclitaxel-induced neuropathic hypersensitivity in mice: responses in 10 inbred mouse strains. Life Sci 74: 2593-2604.

Sommer C, Kress M (2004) Recent findings on how proinflammatory cytokines cause pain: peripheral mechanisms in inflammatory and neuropathic hyperalgesia. Neurosci Lett 361:184-187.

Sorge RE, LaCroix-Fralish ML, Tuttle AH, Sotocinal SG, Austin JS, Ritchie J, Chanda ML, Graham AC, Topham L, Beggs S, Salter MW, Mogil JS (2011) Spinal cord Toll-like receptor 4 mediates inflammatory and neuropathic hypersensitivity in male but not female mice. J Neurosci 31: $15450-15454$.

Sorge RE, Mapplebeck JC, Rosen S, Beggs S, Taves S, Alexander JK, Martin LJ, Austin JS, Sotocinal SG, Chen D, Yang M, Shi XQ, Huang H, Pillon NJ, Bilan PJ, Tu Y, Klip A, Ji RR, Zhang J, Salter MW, et al (2015) Different immune cells mediate mechanical pain hypersensitivity in male and female mice. Nat Neurosci 18:1081-1083.

Stokes JA, Cheung J, Eddinger K, Corr M, Yaksh TL (2013) Toll-like receptor signaling adapter proteins govern spread of neuropathic pain and recovery following nerve injury in male mice. J Neuroinflammation 10: 148.

Suter MR, Berta T, Gao YJ, Decosterd I, Ji RR (2009) Large A-fiber activity is required for microglial proliferation and 338 MAPK activation in the 
spinal cord: different effects of resiniferatoxin and bupivacaine on spinal microglial changes after spared nerve injury. Mol Pain 5:53.

Tanga FY, Nutile-McMenemy N, DeLeo JA (2005) The CNS role of Tolllike receptor 4 in innate neuroimmunity and painful neuropathy. Proc Natl Acad Sci U S A 102:5856-5861.

Taves S, Berta T, Liu DL, Gan S, Chen G, Kim YH, Van de Ven T, Laufer S, Ji RR (2016) Spinal inhibition of p38 MAP kinase reduces inflammatory and neuropathic pain in male but not female mice: sex-dependent microglial signaling in the spinal cord. Brain Behav Immun 55:70-81.

Tursi SA, Lee EY, Medeiros NJ, Lee MH, Nicastro LK, Buttaro B, Gallucci S, Wilson RP, Wong GC, Tükel C (2017) Bacterial amyloid curli acts as a carrier for DNA to elicit an autoimmune response via TLR2 and TLR9. PLoS Pathog 13:e1006315.

Xu ZZ, Kim YH, Bang S, Zhang Y, Berta T, Wang F, Oh SB, Ji RR (2015) Inhibition of mechanical allodynia in neuropathic pain by TLR5mediated A-fiber blockade. Nat Med 21:1326-1331.

Yang Y, Li H, Li TT, Luo H, Gu XY, Lü N, Ji RR, Zhang YQ (2015) Delayed activation of spinal microglia contributes to the maintenance of bone cancer pain in female Wistar rats via P2X7 receptor and IL-18. J Neurosci 35:7950-7963.

Zhang H, Yoon SY, Zhang H, Dougherty PM (2012) Evidence that spinal astrocytes but not microglia contribute to the pathogenesis of paclitaxelinduced painful neuropathy. J Pain 13:293-303.

Zhang H, Li Y, de Carvalho-Barbosa M, Kavelaars A, Heijnen CJ, Albrecht PJ, Dougherty PM (2016) Dorsal root ganglion infiltration by macrophages contributes to paclitaxel chemotherapy-induced peripheral neuropathy. J Pain 17:775-786.

Zhang ZJ, Cao DL, Zhang X, Ji RR, Gao YJ (2013) Chemokine contribution to neuropathic pain: respective induction of CXCL1 and CXCR2 in spinal cord astrocytes and neurons. Pain 154:2185-2197.

Zhang ZJ, Guo JS, Li SS, Wu XB, Cao DL, Jiang BC, Jing PB, Bai XQ, Li CH, $\mathrm{Wu} \mathrm{ZH}, \mathrm{Lu} \mathrm{Y}, \mathrm{Gao}$ YJ (2018) TLR8 and its endogenous ligand miR-21 contribute to neuropathic pain in murine DRG. J Exp Med 215:30193037. 